\title{
Asian summer monsoon prediction in ECMWF System 4 and NCEP CFSv2 retrospective seasonal forecasts
}

\author{
Hye-Mi Kim • Peter J. Webster • Judith A. Curry • \\ Violeta E. Toma
}

Received: 16 September 2011 / Accepted: 20 July 2012/Published online: 7 August 2012

(C) The Author(s) 2012. This article is published with open access at Springerlink.com

\begin{abstract}
The seasonal prediction skill of the Asian summer monsoon is assessed using retrospective predictions (1982-2009) from the ECMWF System 4 (SYS4) and NCEP CFS version 2 (CFSv2) seasonal prediction systems. In both SYS4 and CFSv2, a cold bias of sea-surface temperature (SST) is found over the equatorial Pacific, North Atlantic, Indian Oceans and over a broad region in the Southern Hemisphere relative to observations. In contrast, a warm bias is found over the northern part of North Pacific and North Atlantic. Excessive precipitation is found along the ITCZ, equatorial Atlantic, equatorial Indian Ocean and the maritime continent. The southwest monsoon flow and the Somali Jet are stronger in SYS4, while the southeasterly trade winds over the tropical Indian Ocean, the Somali Jet and the subtropical northwestern Pacific high are weaker in CFSv2 relative to the reanalysis. In both systems, the prediction of SST, precipitation and low-level zonal wind has greatest skill in the tropical belt, especially over the central and eastern Pacific where the influence of El Nino-Southern Oscillation (ENSO) is dominant. Both modeling systems capture the global monsoon and the large-scale monsoon wind variability well, while at the same time performing poorly in simulating monsoon precipitation. The Asian monsoon prediction skill increases with the ENSO amplitude, although the models simulate an overly strong impact of ENSO on the monsoon. Overall, the monsoon predictive skill is lower than the ENSO skill in both modeling systems but both systems show greater predictive skill compared to persistence.
\end{abstract}

H.-M. Kim $(\bowtie) \cdot$ P. J. Webster · J. A. Curry · V. E. Toma School of Earth and Atmospheric Science, Georgia Institute of Technology, 311 Ferst Dr., Atlanta, GA 30332, USA

e-mail: hyemi.kim@eas.gatech.edu

\section{Introduction}

The global monsoon (Webster et al. 1998; Wang et al. 2011a) is a major component of global climate system, affecting the global climate and weather such as floods, droughts and other climate extremes. The Asian monsoon influences almost half of the world's population with their agriculture, life and society depending on monsoon climate. Therefore, understanding the physical processes that determine the character of monsoon systems and also providing accurate extended range predictions on a seasonal timescale is crucial for the economy and policy planning in the monsoon regions. Individual dynamical models and multi-model simulations have played an important role in monsoon prediction. It has been shown that the sensitivity in monsoon prediction/simulation depends on model features, primarily on the presence of ocean-atmosphere coupling, model resolution and improvement of the model physics (Kang et al. 2002; Wang et al. 2005a, and many others). These model improvements are providing substantial advances in seasonal prediction. Several coupled model hindcast intercomparison projects have shown that recent oceanatmosphere coupled models are able to capture the gross feature of Asian monsoon variability from the intraseasonal to seasonal timescales (Kumar et al. 2005; Wang et al. 2005b; Kim et al. 2008; Kug et al. 2008; Wang et al. 2008; Lee et al. 2010).

Several modeling centers routinely provide operational seasonal forecast with ocean-atmosphere coupled model systems. In this study we focus on the European Centre for Medium-Range Weather Forecasts (ECMWF) System 4 and Climate Forecast System version 2 from the National Center for Environmental Prediction (NCEP CFSv2). ECMWF and NCEP have been operating coupled ocean- 
atmosphere seasonal prediction systems since 1997 and 2004, respectively. ECMWF System 3 was introduced in March 2007 (Anderson et al. 2007), showing improved skill for seasonal prediction relative to previous versions (Tompkins and Feudale 2010; Stockdale et al. 2011). Recently, ECMWF upgraded its operational seasonal forecasts to System 4, which has been operational since late 2011. System 4 utilizes ECMWF's the most recent atmospheric model version, with higher resolution and a higher top of the atmosphere, more ensemble members and a larger reforecast data set (Molteni et al. 2011). The NCEP CFSv1 has been examined in simulating and predicting El Nino-Southern Oscillation (ENSO) variability (Wang et al. 2005b); Asian-Australian/Indian monsoon (Yang et al. 2008; Liang et al. 2009; Pattanaik and Kumar 2010) and climatic variation in the U.S. (Yang et al. 2009). The NCEP CFSv2 (http://cfs.ncep.noaa.gov/) is an upgraded version of CFSv1 (Saha et al. 2006) and became operational since 2011. The NCEP CFSv2 represents a substantial change from CFSv1 in all aspects of the forecast system including model components, data assimilation system and ensemble configuration, and shows important advances in operational prediction (Weaver et al. 2011).

The capabilities of individual coupled systems for predicting the Asian monsoon have been analyzed previously for various target seasons, different regions and a wide range of variables. However, the ECMWF system 4 and NCEP CFSv2, which are the most recently upgraded systems, have not been compared using the same validation methods. An overall assessment of simulation ability and prediction skill of these two modeling systems will be of interests to the scientific, operational and user communities, providing information to support the choice of which model(s) to use. In Kim et al. (2012), the seasonal prediction skill and the simulation ability for ENSO teleconnection for the boreal winter in ECMWF system 4 and NCEP CFSv2 have been compared. Here, we compare the simulated climate variability and seasonal prediction skill for the Northern Hemisphere $(\mathrm{NH})$ summer monsoon, with special focus on the Asian monsoon region. Section 2 introduces details of the reforecasts and observation data sets. Section 3 examines the simulation and prediction of monsoon in the two modeling systems. Section 4 focuses on the ENSO and the monsoon prediction capabilities. Discussion for the failure in monsoon prediction is given in Sect. 5 and the summary in Sect. 6.

\section{Data}

ECMWF System 4 (hereafter SYS4) and NCEP CFSv2 (hereafter CFSv2) are fully coupled atmosphere-ocean forecast systems that provide operational seasonal predictions together with reforecast data to evaluate and calibrate the models. The SYS4 seasonal reforecasts include 15 member ensembles and consist of 7 month simulations initialized on the 1st day of every month from 1981 until 2010. Details for the ECMWF System 4 can be found in at www.ecmwf.int/products/forecasts/seasonal/documentation/ system4. The CFSv2 reforecasts are a set of 9-month reforecasts initiated every 5 th day with four ensemble members for the period from 1982 to 2010. Initial conditions for the atmosphere and ocean come from the NCEP Climate Forecast System Reanalysis (CFSR, Saha et al. 2010). Details of the system can be found in http://cfs.ncep.noaa.gov.
Fig. 1 Climatological summer mean (JJA) bias (modelobservation) of (top) SST (K) and (bottom) precipitation $(\mathrm{mm} /$ day) for $(\mathbf{a}, \mathbf{c})$ SYS4 and (b, d) CFSv2

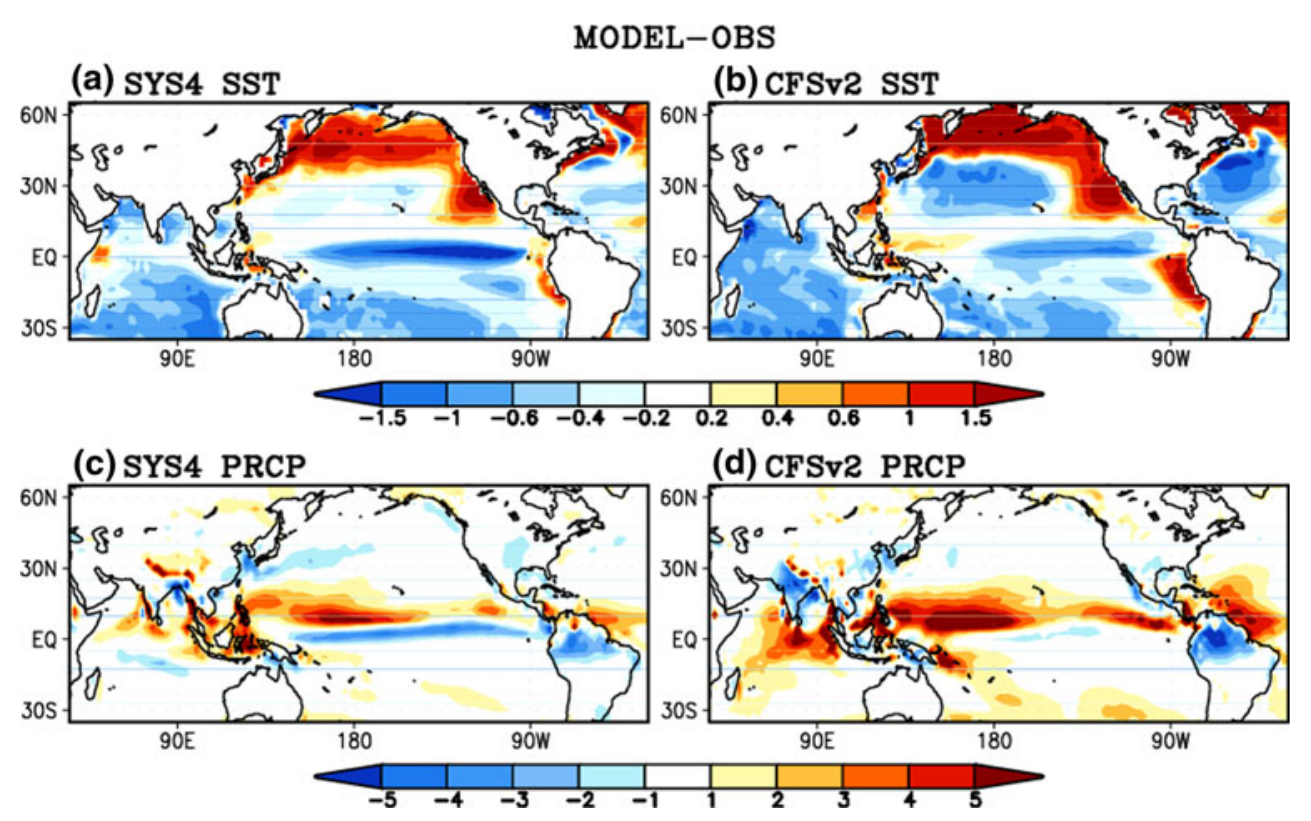


Fig. 2 Climatological wind vector and zonal wind anomaly at $850 \mathrm{hPa}$ (shading) in (a) ERA interim and biases of (b, d) SYS4 and (c, e) CFSv2 from ERA interim and CFS reanalysis
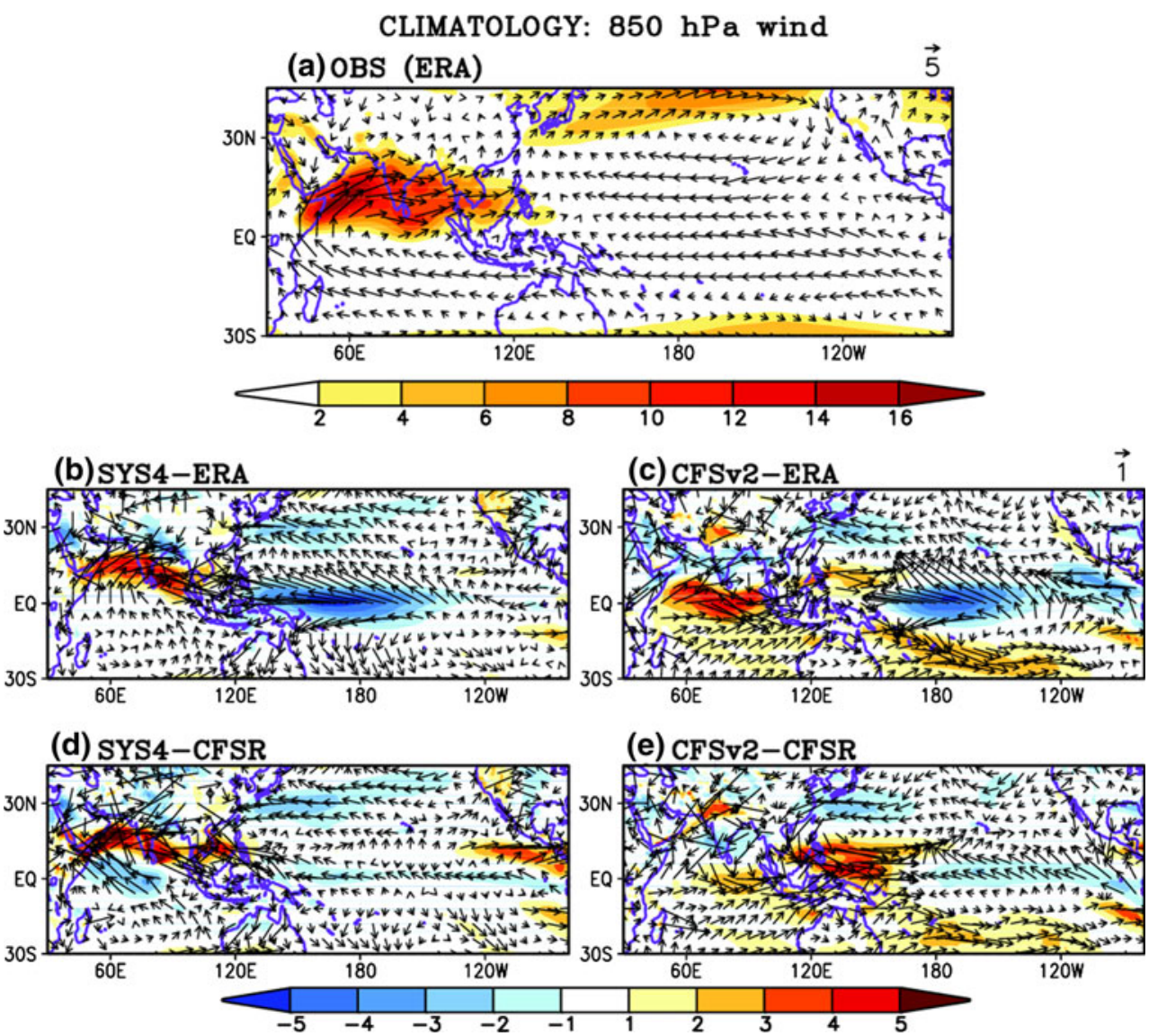

We investigated the forecasts initialized in spring with the aim of assessing the prediction skill of the boreal summer season. We match the ensemble size, as well as lead-time for the comparison of the SYS4 and CFSv2 forecasts, as prediction skill depends strongly on the ensemble size (Kumar and Hoerling 2000). The SYS4 reforecast set consists of 15 ensemble members initialized on May 1st. The CFSv2 set consists of 16 ensemble members initialized from April 21st to May 6th. Particular variables are followed from their initial date through June to August (JJA), which we define as the period of the $\mathrm{NH}$ summer. A total of $28 \mathrm{NH}$ summers are examined in the 1982-2009 period.

For forecast evaluation, Global Precipitation Climatology Project (GPCP) version 2.1 combined precipitation dataset (Adler et al. 2003) is used. Sea surface temperature (SST) data is obtained from monthly NOAA Optimum Interpolation SST V2 (Reynolds et al. 2002). The wind data at $850 \mathrm{hPa}$ and $200 \mathrm{hPa}$ are obtained from the ERAInterim (Berrisford et al. 2009) and CFSR products. ERAInterim (hereafter ERA) is the latest global atmospheric reanalysis dataset produced by the ECMWF. The CFSR is a major improvement over the first generation NCEP reanalyses (NCEP R1 and R2) and is the product of a coupled ocean-atmosphere-land system at higher spatial resolution (Saha et al. 2010).

\section{Monsoon simulation and prediction}

\subsection{Seasonal mean bias and prediction skill}

To assess the general capability of the two modeling systems in simulating and predicting seasonal mean climate variability, we first compare their seasonal mean biases. The long-term mean of the 28 year simulation of ensemble mean for SST, precipitation and low level winds for the $\mathrm{NH}$ summer are compared with the observations (Figs. 1,2). Although the simulated climatology in both modeling systems generally matches the observed patterns, systematic biases are found. In both systems, a cold bias of SST occurs over the equatorial Pacific, North Atlantic, Indian Ocean and a broad region over the Southern Hemisphere. A warm bias is found over the northern part of North Pacific and North Atlantic (Fig. 1a, b). These findings are similar to the NH winter biases (Kim et al. 2012). In the ENSO region, a strong cold bias is apparent in both systems and a strong warm bias is found in the cold tongue region in 
Fig. 3 The climatological mean for the annual range of precipitation ( $\mathrm{mm} /$ day) defined by the boreal summer mean (JJA) minus winter mean (DJF) precipitation in (a) observation, (b) SYS4 and (c) CFSv2. Contour interval is $5 \mathrm{~mm} /$ day

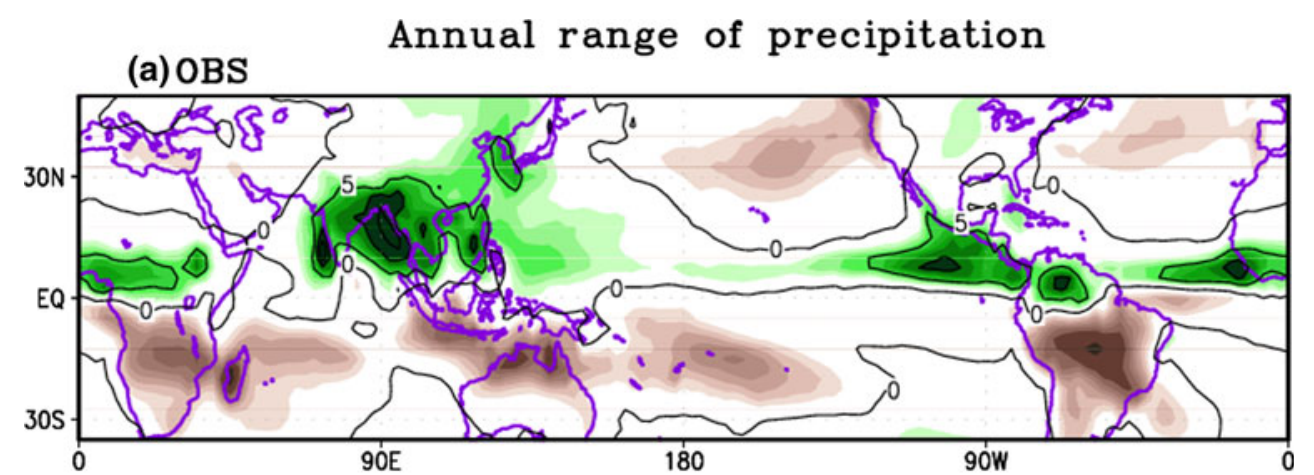

(b) SYS4

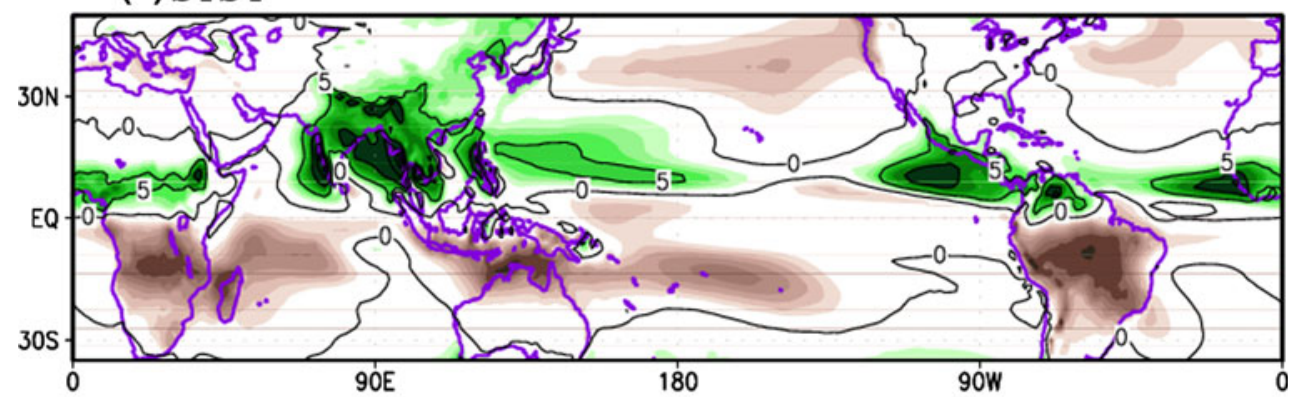

(c) CFSv2

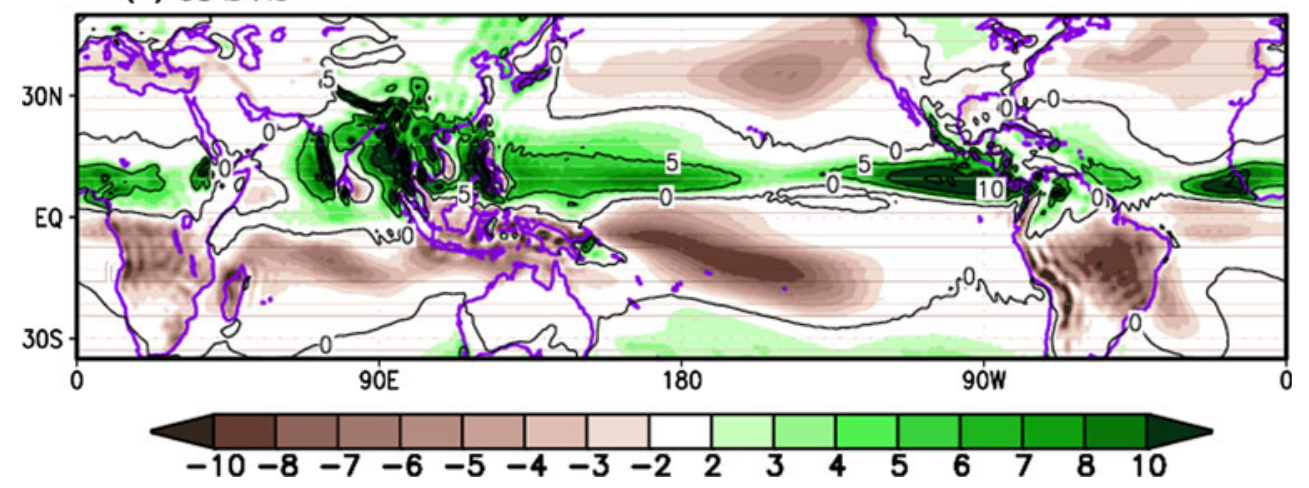

CFSv2 (Fig. 1a, b). The summer mean precipitation shows an excessive precipitation along the Inter-Tropical Convergence Zone (ITCZ), equatorial Atlantic, equatorial Indian Ocean and maritime continent (Fig. 1c, d). Both systems show a dry bias over the East Asia monsoon region and northern part of South America. In SYS4, a strong dry bias is found over equatorial central Pacific (Fig. 1c, d).

The monsoon climate is defined as a shift in the wind direction caused by differential heating of major landmasses and adjacent oceans that brings about seasonal wet and dry rainfall anomalies over the monsoon area. Figure 2 shows the climatology of $850 \mathrm{hPa}$ lower tropospheric wind in ERA interim (Fig. 2a) and biases in both modeling systems (Fig. 2b-e). As the climatology patterns are slightly different between ERA interim and CFSR, we show the bias from both ERA interim (Fig. 2b, c) and CFSR (Fig. 2d, e). An issue in evaluating the reforecast is the choice of the reanalysis. Kim et al. (2012) showed that the predictive skill of the surface temperature of the two models depends on the reanalysis dataset used due to discrepancies and uncertainties associated with the reanalysis. Therefore, the analyses in this study were conducted using both reanalysis datasets.

The observed NH summer mean circulation pattern (Fig. 2a) is characterized by the easterly trade wind over the equatorial Pacific, anti-cyclonic flow in the North Pacific, southwest monsoon flow over the tropical Asia and the cross-equatorial Somali Jet in the Indian monsoon region. These major circulation features are captured in each reanalysis set. However, the southwest monsoon flow and the Somali Jet are stronger in SYS4 but weaker in CFSv2 relative to both reanalyses (Fig. 2b-e). The strong monsoon flow in SYS4 is dynamically consistent with the high precipitation in the western Indian Ocean, while the bias of monsoon flow in CFSv2 is consistent with the wet anomaly in the equatorial Indian Ocean. In CFSv2, the southeasterly trade winds over the tropical Indian Ocean, the Somali Jet and the subtropical northwestern Pacific 
Fig. 4 Correlation coefficients for (first line) SST (second line) precipitation and zonal wind at $850 \mathrm{hPa}$ with (third line) ERA interim and (fourth line) CFS reanalysis for (left) SYS4 and (right) CFSv2. Solid black (gray) line represents statistical significance of the correlation coefficients at $99 \%(95 \%)$ confidence level (a) SYS4: SST

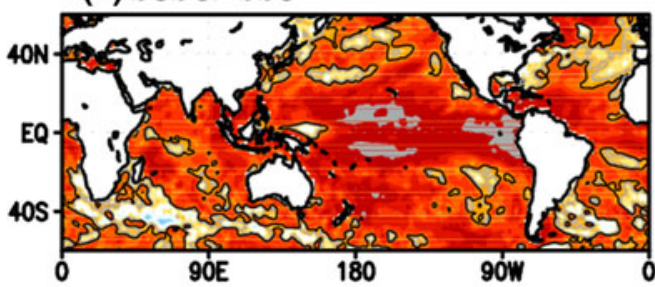

(c) SYS4: PRCP

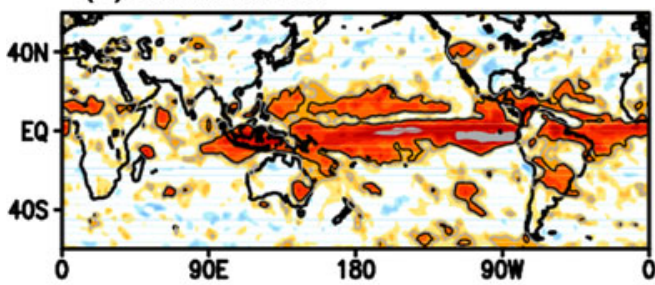

(e) SYS4: U850_ERA

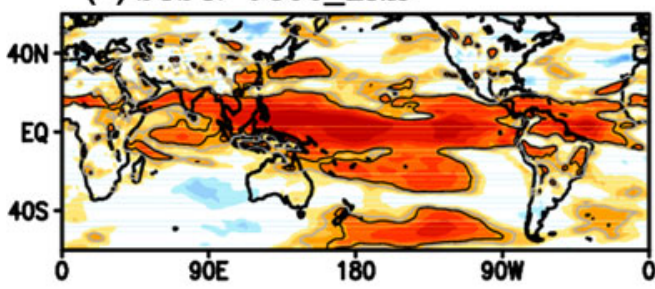

(g) SYS4: U850_CFSR

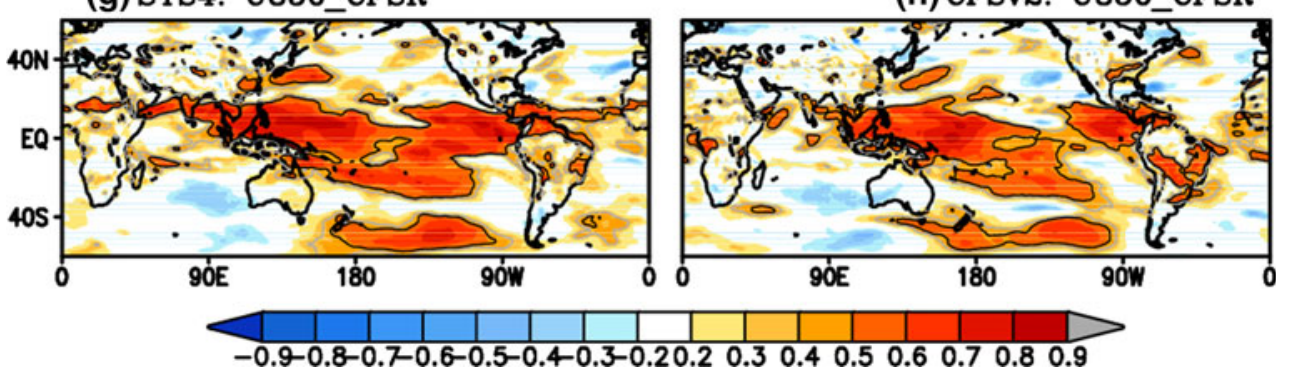

(b) CFSv2: SST

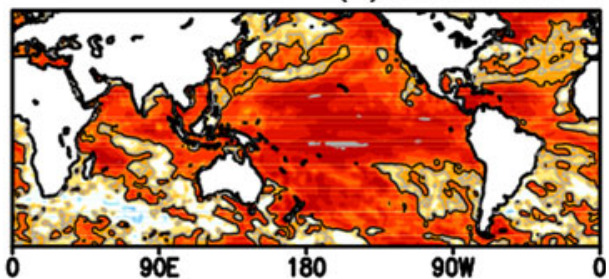

(d) CFSv2: PRCP

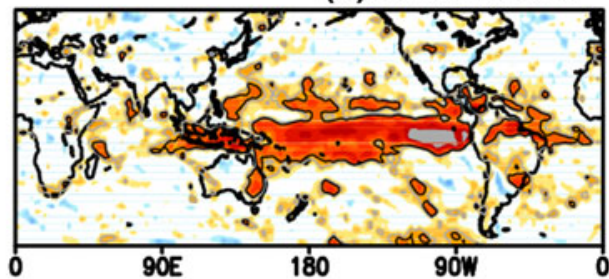

(f) CFSv2: U850_ERA

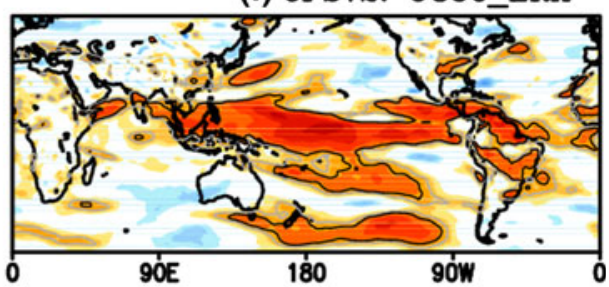

(h) CFSv2: U850_CFSR high are weaker than observed in a manner similar to CFSv1 (Yang et al. 2008). In both modeling systems, the stronger-than-observed easterly trade wind and convergence over the western North Pacific is consistent with the wet bias over the western Pacific warm pool and central Pacific (Fig. 1c, d). The weaker-than-observed anticyclonic flow over the western North Pacific and weaker southerly from South China Sea is consistent with the deficiency of East Asian monsoon precipitation as less water vapor is transported to the monsoon region. These biases over the Asian monsoon region were also found in previous studies (Yang et al. 2008; Lee et al. 2010). The mean bias in the two simulations relative to the CFSR shows similar characteristics to the mean bias with ERA interim but with regional differences (Fig. 2d-e).

Wang and Ding (2008) proposed a set of metrics to assess model performance in simulating the mean climate and annual cycle of the global monsoon. The metrics include evaluation of the annual mean skill and the predictive skill of the leading modes of annual variation. Lee et al. (2010) applied these metrics to evaluate the performance of 13 coupled models simulating the global monsoon. The first mode that represents a solstice global monsoon mode can be reproduced by the differences between summer and winter precipitation (Wang and Ding 2008). The simulation ability of the global monsoon mode is assessed by the annual range (AR) of precipitation defined as JJA mean minus DJF mean precipitation. JJA (DJF) mean precipitation is 1-3 lead month average that uses May (November) initial condition. Details for the reforecasts data for $\mathrm{NH}$ winter (DJF) are described in Kim et al. (2012). The AR of the simulated precipitation fields is compared with the GPCP satellite-based observations in Fig. 3. Both modeling systems simulate the solstice global monsoon mode well with good representation of the AsianAustralian and Africa monsoons. The model bias is consistent with the precipitation bias shown in Fig. 1. The major deficiencies of the AR precipitation in SYS4 forecast 
Fig. 5 Monsoon indices: (a) WY index (b) IM index and (c) WNPM index from 1982 to 2009 for ERA interim (black), CFS reanalysis (gray), SYS4 (red) and CFSv2 (blue).

Numbers indicate the temporal correlation coefficient (multiplied by 100) compared with (left) ERA interim and (right) CFS reanalysis
(a)WY index

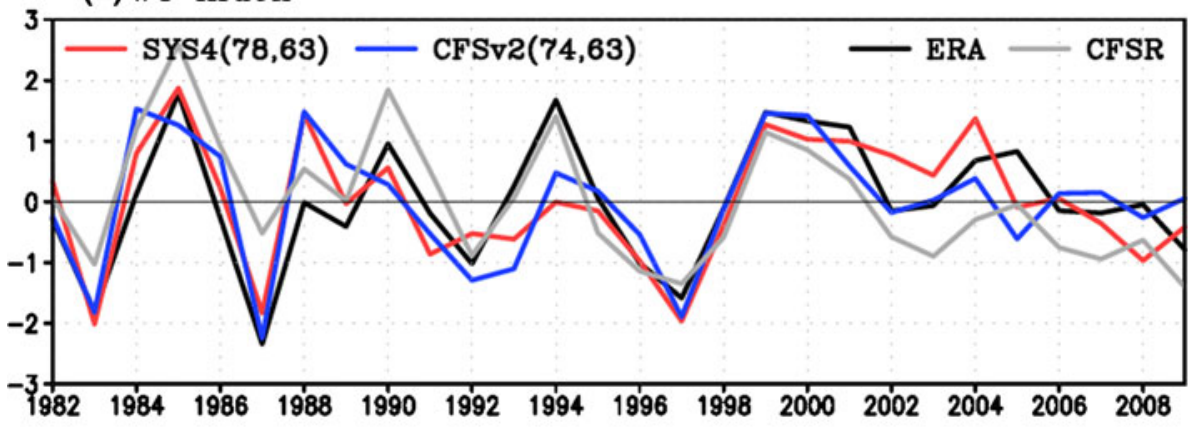

(b) IM index

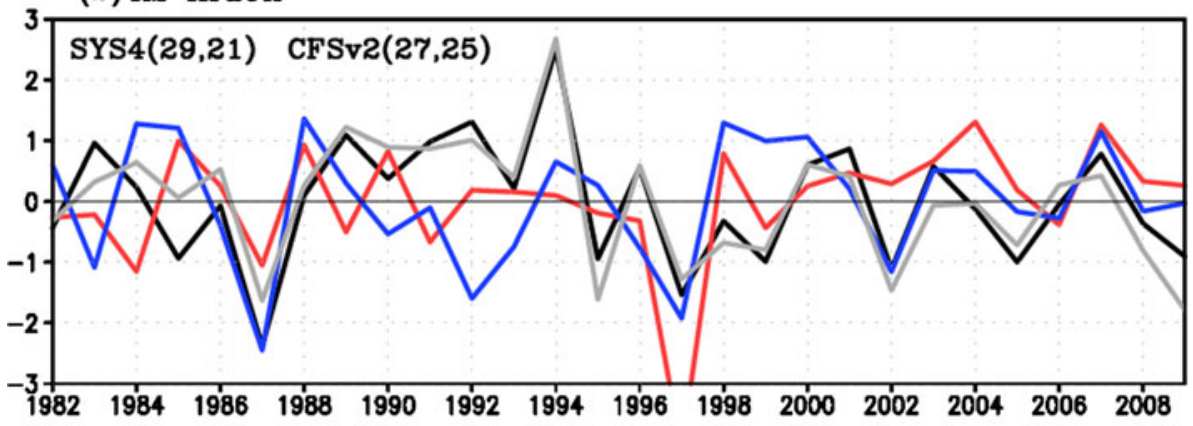

(c) WNPM index

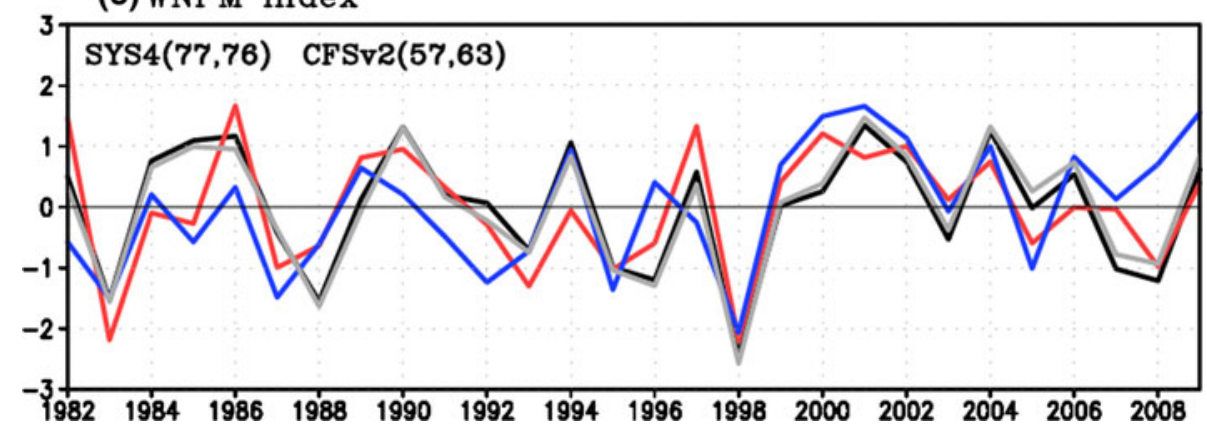

are found over the South China Sea and in the East Asian monsoon, whereas wet biases are found over the ITCZ, equatorial Atlantic and maritime continent. In CFSv2, an excessive AR precipitation is found along the ITCZ, especially over the western to central Pacific and equatorial Atlantic.

To examine the seasonal mean prediction skill in both systems, the correlation coefficients between the observation and the reforecast anomalies are calculated for the ensemble mean over 28 years. Figure 4 shows the JJA mean seasonal prediction skill for SST, precipitation and $850 \mathrm{hPa}$ zonal wind anomaly from simulations initialized on or around May 1st. In both systems, the skill for all three variables is greater over the tropical Pacific than over the extra-tropics and greater over the ocean than over land (Peng et al. 2000, 2011). SST prediction has its greatest skill in the tropical belt, especially over the central to eastern Pacific and equatorial Atlantic where the influence of ENSO is dominant (Fig. 4a-b). SST prediction skill is statistically significant at the $99 \%$ confidence level in most of the regions. The precipitation prediction skill is generally lower than that of the SST. It also has the greatest skill over the equatorial Pacific but the significant values are only limited over the equatorial Pacific (Fig. 4c, d). Figure 4 shows that the Asian monsoon region, especially the Indian Ocean, has low skill in precipitation where the correlation coefficients do not exceed the significant confidence level. The skill of the lower tropospheric zonal wind prediction is compared with both the ERA interim and CFSR. The SYS4 shows greater skill over the tropical Pacific and Indian Ocean compared to CFSv2 when the simulations are compared with both ERA interim and CFSR (Fig. 4e-h). The better performance of SYS4 in simulating the lower tropospheric circulation field in the Asian monsoon region may result in the higher prediction skill for the monsoon indices compared to CFSv2. 


\subsection{The Asian summer monsoon}

We now examine the capability of SYS4 and CFSv2 in simulating the spatial pattern and the year-to-year variability of the Asian summer monsoon. Several monsoon indices are compared between the reforecasts and the two reanalyses (ERA interim and CFSR). Webster and Yang (1992) introduced a monsoon circulation index (hereafter WYI) defined by zonal wind shear between 850 and $200 \mathrm{hPa}$ averaged over the South Asia from $40^{\circ}$ to $110^{\circ} \mathrm{E}$ and from the equator to $20^{\circ} \mathrm{N}$, reflecting the year-to-year variability of the broad scale South Asian summer monsoon. The Indian monsoon index (IMI) and the western North Pacific monsoon index (WNPMI) were introduced by Wang et al. (2001). The IMI is defined as the difference between the $850 \mathrm{hPa}$ zonal winds between $5^{\circ}-15^{\circ} \mathrm{N}, 40^{\circ}-$ $80^{\circ} \mathrm{E}$ and $20^{\circ}-30^{\circ} \mathrm{N}, 70^{\circ}-90^{\circ} \mathrm{E}$ while the WNPMI is defined as the $850 \mathrm{hPa}$ zonal wind difference between a southern region $\left(5^{\circ}-15^{\circ} \mathrm{N}, 100^{\circ}-130^{\circ} \mathrm{E}\right)$ and a northern region $\left(20^{\circ}-30^{\circ} \mathrm{N}, 110^{\circ}-140^{\circ} \mathrm{E}\right)$ in the Asian monsoon domain. The IMI and WNPMI represent the dominant modes of interannual variability of the Indian summer monsoon and western North Pacific summer monsoon, respectively (Wang et al. 2001). Each index shows robust interannual variability over the 28 year period (Fig. 5). The numbers in parentheses refer to the correlation coefficients (multiplied by 100) between the reforecasts and the ERA interim and CFSR, respectively. The limiting value of significant correlation coefficient is $0.47(0.37)$ at the 99 (95) \% level.

Comparing with the ERA interim, the interannual variation of WYI is quite well reproduced by both reforecasts, with correlation coefficient of 0.78 and 0.74 for SYS4 and CFSv2, respectively, which exceeds $99 \%$ statistical significant level. The correlations between CFSR and the predicted index are 0.63 for both modeling systems (Fig. 5a). Although the low level zonal wind is not well reproduced in either reforecast data set (Fig. 3c), the high skill of WYI could result from the high skill in the upper level zonal wind (not shown). However, the IMI shows insignificant skill, ranging from 0.2 to 0.3 in both reforecast products (Fig. 5b). Both models perform poorly in capturing the variability of the monsoon component measured by IMI, given the difficulties in simulating the circulation field for Indian monsoon region. The low prediction skill in IMI could result from the small area used to define the index. The WNPMI (Fig. 5c) is well captured in both modeling systems, having correlation coefficient ranging from 0.57 to 0.77 .

To measure the variability of the monsoon precipitation, first we compare the variability of the model precipitation with the observations (GPCP) over the Asian monsoon region for each forecast system (Fig. 6). The (a) OBS

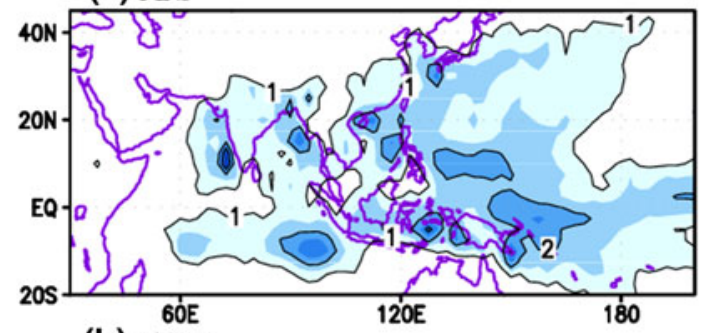

(b) SYS4

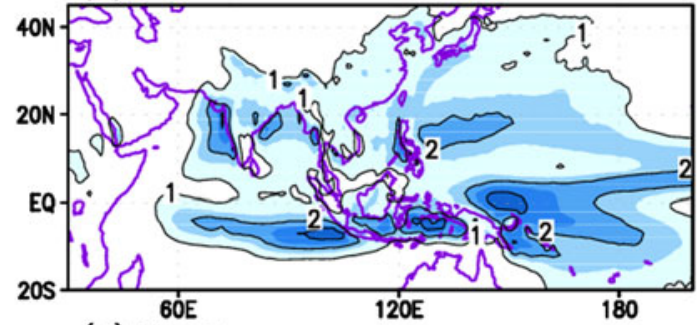

(c) CFSv2
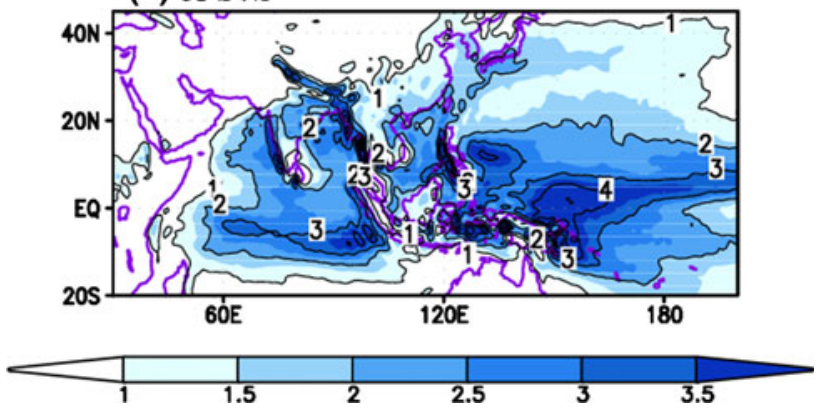

Fig. 6 Standard deviation of JJA precipitation ( $\mathrm{mm} /$ day) for (a) GPCP, (b) SYS4 and (c) CFSv2

variability is calculated using the standard deviation of JJA mean precipitation anomalies over the 28 year period. The standard deviation of the forecast precipitation anomalies for each ensemble member is calculated individually and then averaged. Both modeling systems show similar gross patterns to the observations with maximum variability over the Bay of Bengal, southern part of China Peninsula, southeastern Indian Ocean, tropical western Pacific, maritime continent and the East Asian monsoon region (Fig. 6). CFSv2 overestimates the amplitude of the variability over the entire Asian monsoon region about 2-3 times and SYS4 overestimates the amplitude along the equator.

To analyze the variance and the systematic bias of the Asian monsoon variability in both modeling systems, an empirical orthogonal function (EOF) analysis is applied to both the observed and predicted JJA precipitation anomaly over the area of $40^{\circ}-240^{\circ} \mathrm{E}$ and $25^{\circ} \mathrm{S}-40^{\circ} \mathrm{N}$. The EOF analysis is applied to the predicted anomaly of individual ensemble member and then averaged. Figure 7 represents the eigenvector of the first and second EOF mode from observations and for the two modeling systems. The two 
Fig. 7 Eigenvectors of the (left) first and (right) second EOF mode for JJA precipitation anomaly for (top) observation, (middle) SYS4 and (bottom) CFSv2. Numbers indicate (left) the percentage of total variance of precipitation anomaly and (right) the pattern correlation coefficient with observation

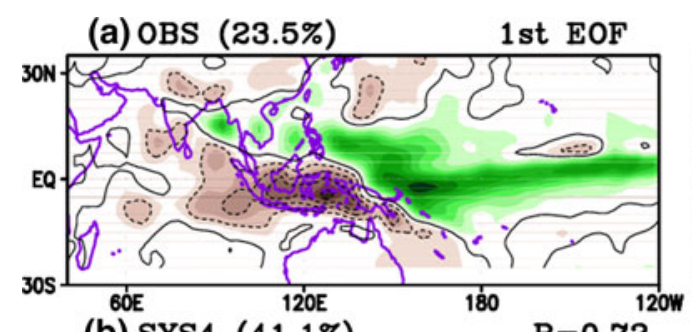

(d) OBS (10.6\%)

2nd EOF

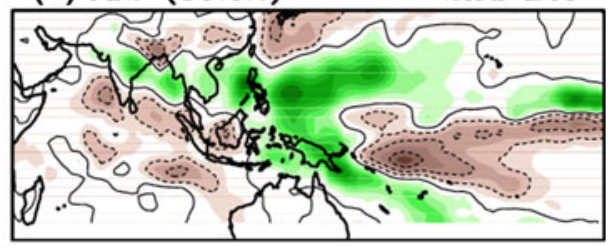

(b) SYS4 (41.1\%)
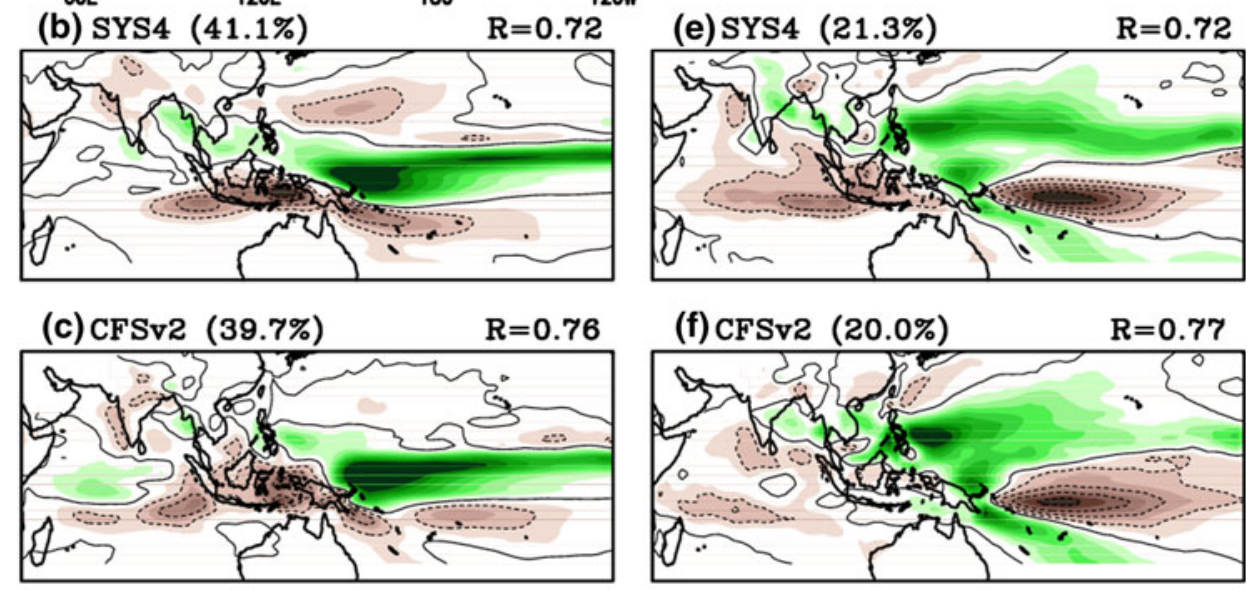

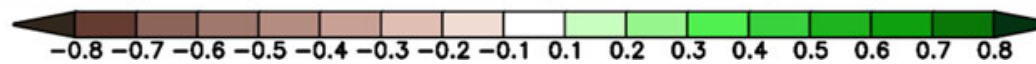

leading EOF modes of the observed fields explain almost $34 \%$ of the total variance (Fig. 7a) and have distinct relationship with ENSO. The first mode explains $23 \%$ of the total variance and the eigenvector is characterized by positive components over the central and equatorial eastern Pacific where the wet anomalies extend northwestward to the Philippine Sea, the northern South China Sea and the
Bay of Bengal. This mode is associated with the transition from warming to cooling in the eastern-central Pacific in El Nino summer (Wang et al. 2008). The strong ENSO forcing modulates the Walker circulation inducing sinking motion (negative precipitation anomaly) over the western Pacific, especially over the maritime continent and the equatorial eastern Indian Ocean (Fig. 7a). The second
Fig. 8 Principal components of the first and second EOF modes of precipitation anomalies from observation (black), SYS4 (red) and CFSv2 (blue). Numbers indicate the correlation coefficient between reforecasts and observation over 28 years
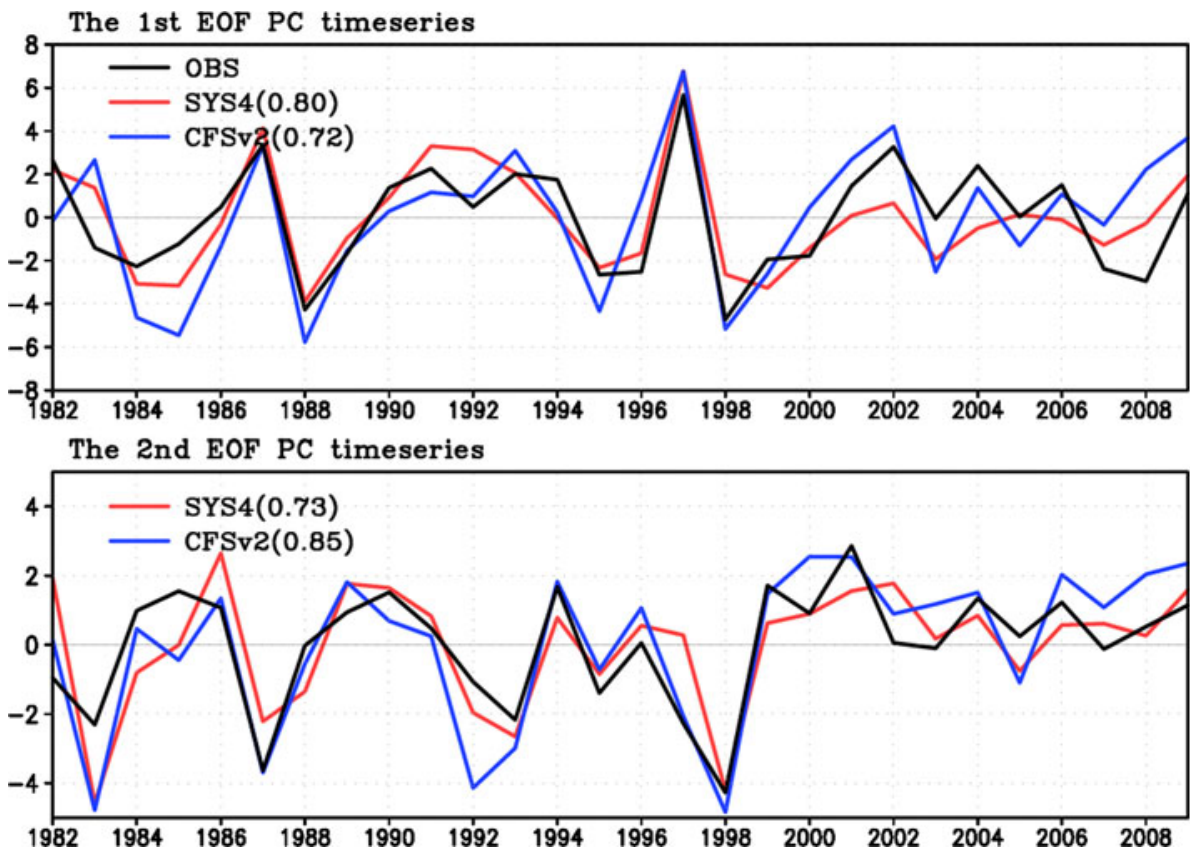


\section{Composite: PRCP and $850 \mathrm{hPa}$ wind anom.}

(a) OBS: El Nino

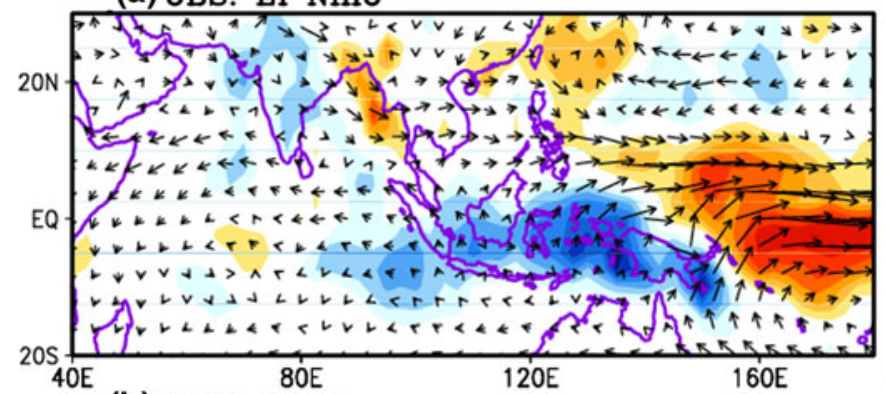

(b) SYS4: El Nino

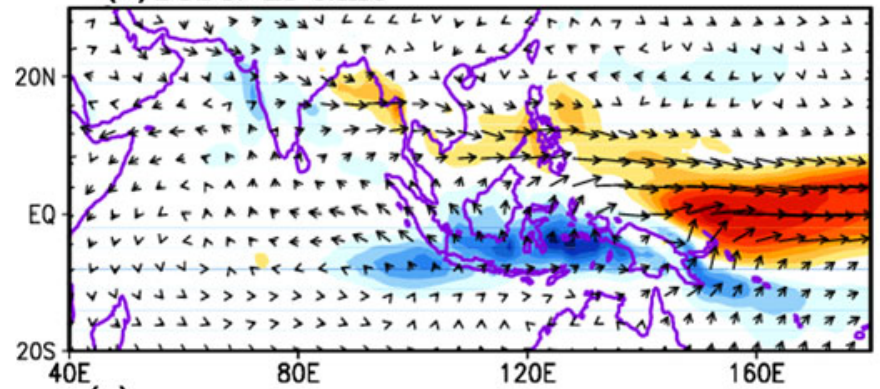

(c) CFSv2: El Nino

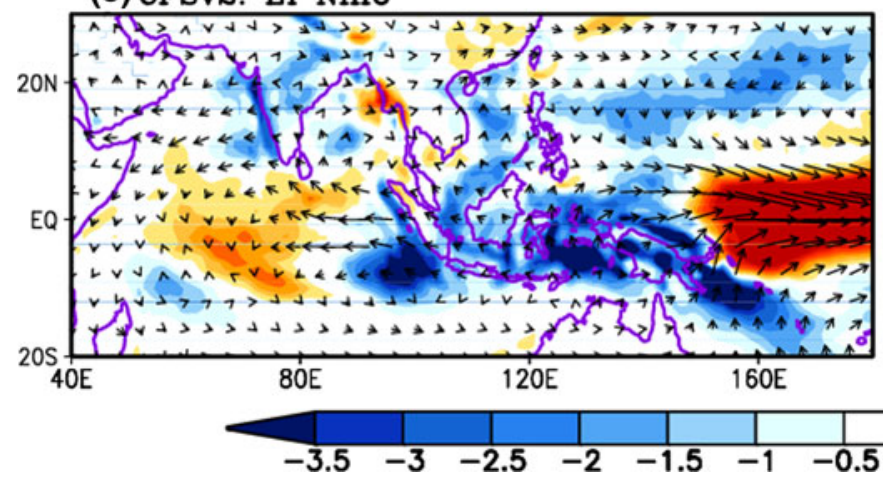

(d) OBS: La Nina

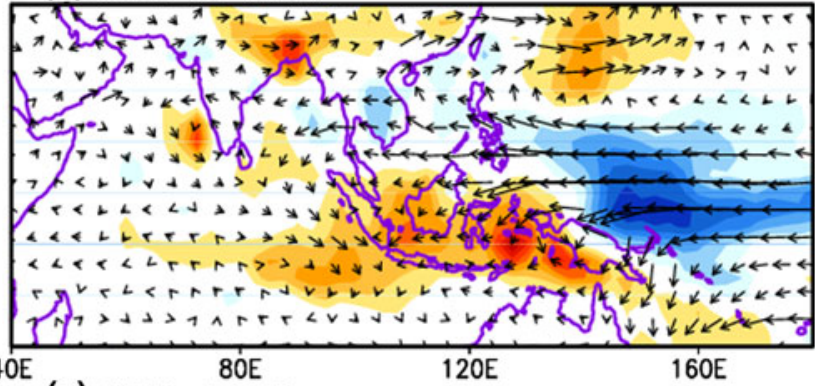

(e) SYS4: La Nina

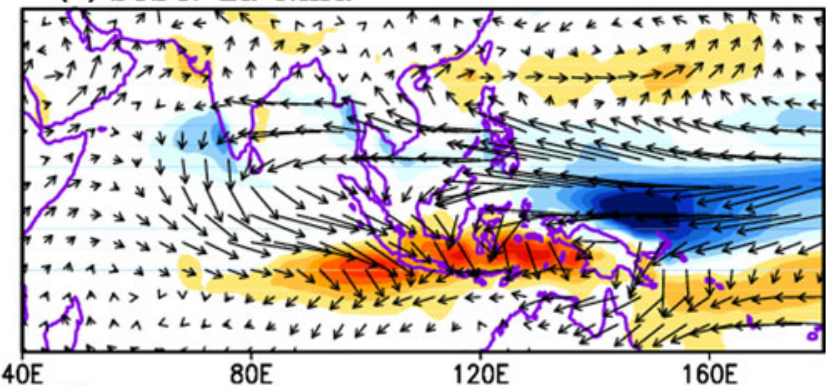

(f) CFSv2: La Nina

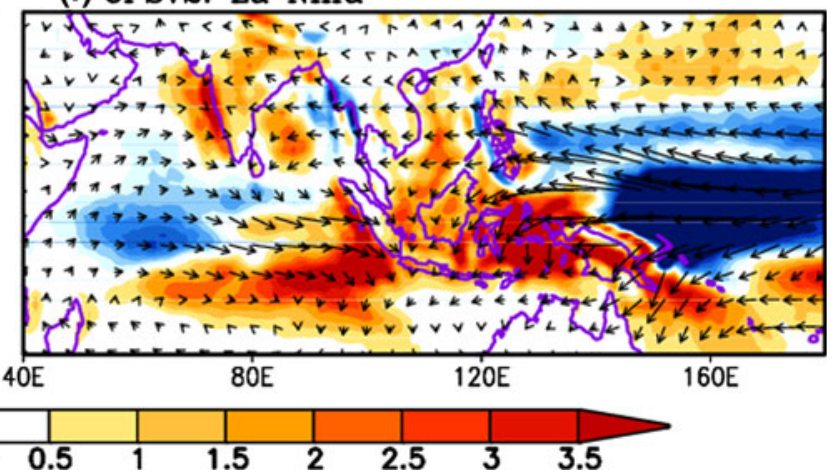

Fig. 9 Composite map of precipitation (mm/day, shading) and $850 \mathrm{hPa}$ wind anomaly (m/s) for (top) GPCP and ERA interim, (middle) SYS4 and (bottom) CFSv2 for (left) El Nino and (right) La Nina summer

mode explains $10 \%$ of the total variance and has been known to be a precursor feature in the summer prior to a year in which El Nino develops (Wang et al. 2008). The spatial pattern of the second mode shows positive anomaly over the WNP region and negative anomalies over the central Pacific and equatorial Indian Ocean (Fig. 7d). In both systems, the percentage of total variance of precipitation anomalies is larger than that of the observations, associated with an overly strong modulation of the Asian monsoon by ENSO.

The spatial patterns of eigenvectors in the models are slightly different from the observations. For the first eigenvector, both SYS4 and CFSv2 capture the positive anomalies over the central to eastern Pacific and the negative anomalies over the maritime continent and eastern Indian Ocean, but they do not represent correctly the anomalies over the North Pacific and western Indian Ocean (Fig. 7b, c). The pattern correlation of the first eigenvector between the reforecasts and observation is 0.72 and 0.76 in SYS4 and CFSv2, respectively. For the second mode, the SYS4 and CFSv2 capture the gross pattern but have strong dry anomalies over the equatorial central Pacific and equatorial Indian Ocean in SYS4 (Fig. 7e) and wet anomalies over the Philippine Sea in CFSv2 (Fig. 7f). The spatial correlation of the second eigenvector between reforecasts and observations is 0.72 and 0.77 in SYS4 and CFSv2, respectively. The eigenvectors and their corresponding time series of principal component (PC) of the two leading modes are related to ENSO variability. As mentioned above, the first mode is associated with the transition from warming to cooling in the eastern-central Pacific, whereas the second mode 
Fig. 10 Anomaly pattern correlation for (a) global region and (b) Asian Monsoon region of the zonal wind at $850 \mathrm{hPa}$ for SYS4 (red), CFSv2 (blue) and persistence prediction (green). The gray bar represents the ENSO amplitude for boreal summer. Numbers indicate the mean correlation coefficient over 28 years (a) Global region

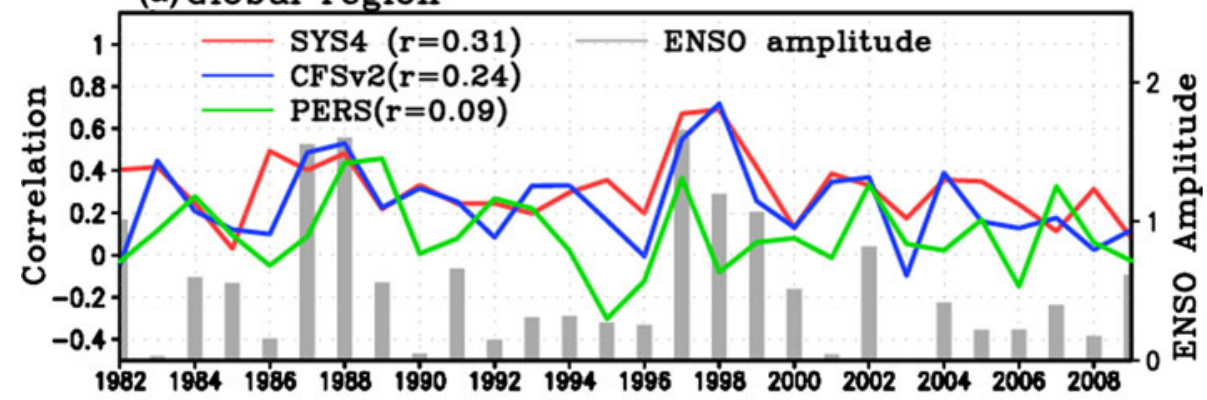

(b) Asian Monsoon region

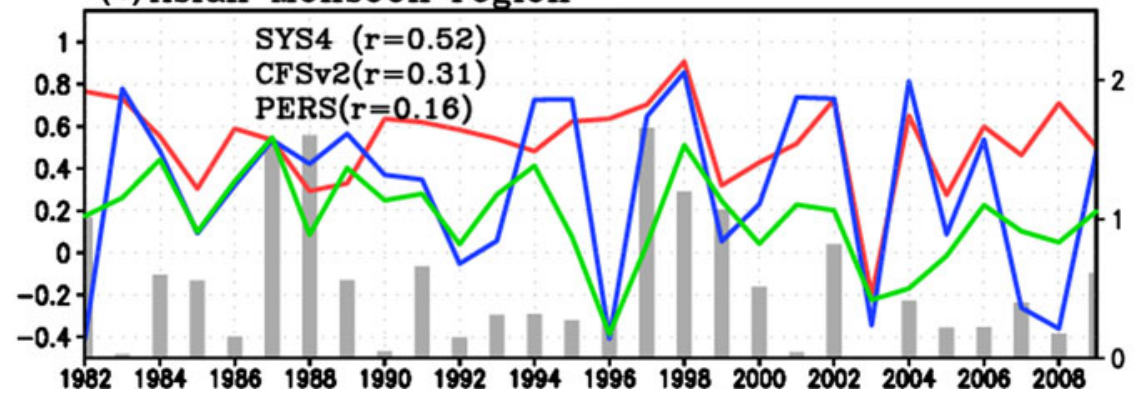

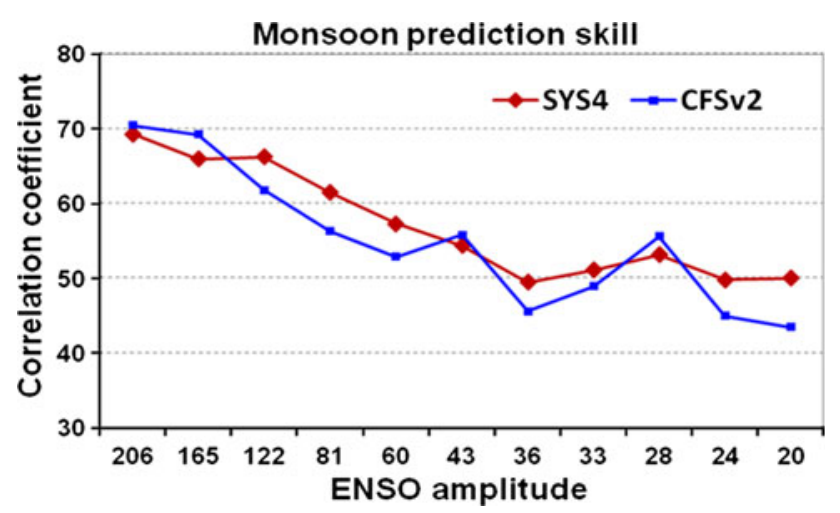

Fig. 11 Prediction skill of zonal wind at $850 \mathrm{hPa}$ over the Asian monsoon area $\left[40^{\circ}-150^{\circ} \mathrm{E}, 20^{\circ} \mathrm{S}-30^{\circ} \mathrm{N}\right]$ as a function of ENSO amplitude from Fig. 10b. ENSO amplitude and correlation coefficients are multiplied by 100 . Years are arranged in the ascending order of ENSO amplitude

provides a precursor for ENSO development (Wang et al. 2008). The PC time series for the models capture the dominant ENSO variability, although the model's eigenvectors show biases in their spatial pattern. The correlations between predicted and observed PC time series for the first and second mode range from 0.7 to 0.85 (Fig. 8).

\section{ENSO and the monsoon prediction}

Previous results show that the Asian monsoon is strongly modulated by the ENSO forcing in both the observation and model predictions. ENSO is generally well predicted (up to 6 month) in seasonal forecast models (Jin et al. 2008) at least after the April/May "predictability barrier" (Webster and Yang 1992; Webster 1995). For SYS4 and CFSv2, the correlation coefficients between the observed and predicted JJA Nino 3.4 index is 0.87 and 0.83 , respectively. The slightly lower skill in CFSv2 compared to SYS4 could result from the shift in SST bias associated with the changes in satellite observations that were assimilated in the CFSR (Xue et al. 2011; Wang et al. 2011b; Kim et al. 2012).

To assess the ENSO-monsoon relationship, we first compare the predicted spatial patterns determined by the ENSO forcing. Figure 9 shows the composite map of JJA precipitation (GPCP) and 850-hPa wind (ERA) anomalies in four strong El Nino (1982, 1987, 1997 and 2002) and La Nina (1984, 1988, 1998 and 1999) summers. The El Nino and La Nina years are defined by the normalized Nino 3.4 index exceeding one standard deviation. The traditional $\mathrm{El}$ Nino pattern is produced by s a shift of the Walker circulation, inducing ascending motion with a wet anomaly across the equatorial central to eastern Pacific and sinking motion with a dry anomaly over the maritime continent and equatorial eastern Indian Ocean (Fig. 9a). Increased rainfall in the central to eastern Pacific is associated with the cyclonic pattern and the convergence of $850 \mathrm{hPa}$ winds, while the dry rainfall anomalies are linked to the anticyclone pattern and the divergence of the $850 \mathrm{hPa}$ winds. Although the La Nina pattern is not exactly a mirror image of El Nino, the gross patterns are almost opposite from El Nino (Fig. 9d). Both modeling systems simulate well the gross pattern of the ENSO response, although the 


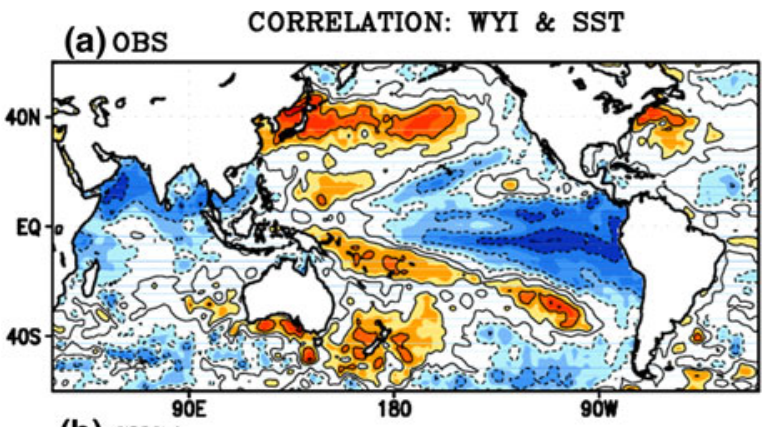

(b) SYS4

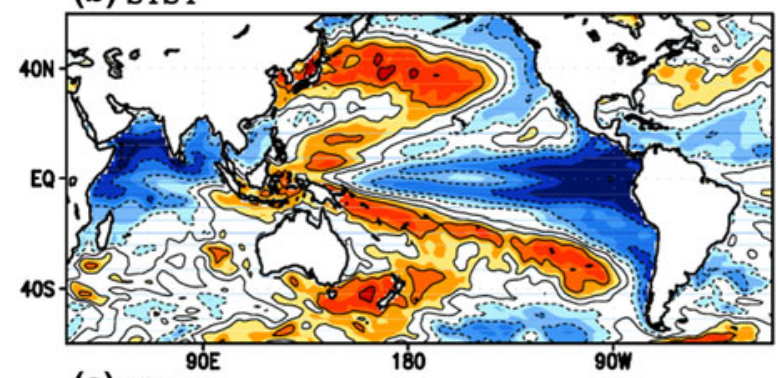

(c) $\mathrm{CFSv}_{2}$

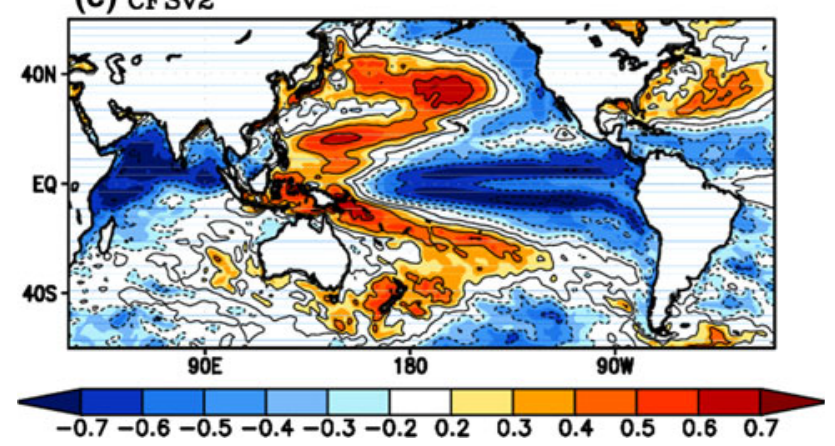

Fig. 12 Correlation coefficients between JJA Webster and Yang index (WYI) and SST anomaly for (a) observation, (b) SYS4 and (c) CFSv2

magnitudes are larger than the observed anomalies, especially in CFSv2.

To assess the impact of ENSO on the monsoon prediction skill, the pattern correlation between the predictions and the reanalysis (ERA interim) in $850 \mathrm{hPa}$ zonal wind is calculated over the entire globe $\left(0-360^{\circ} \mathrm{E}, 70^{\circ} \mathrm{S}-70^{\circ} \mathrm{N}\right)$ and the Asian monsoon region $\left(40-150^{\circ} \mathrm{E}, 20^{\circ} \mathrm{S}-30^{\circ} \mathrm{N}\right)$ over the 28 summers. For comparison, the persistence skill has been included. The zonal wind anomaly in the month previous to the starting date is used as a measure of persistence. For example, the 3-month-persistence (JJA) hindcasts starting on the 1st of June are obtained from the anomaly of the previous May. Figure 10 shows the year-toyear variability of the $850 \mathrm{hPa}$ zonal wind prediction skill with ENSO amplitude. The ENSO amplitude is defined as a standard deviation of JJA mean Nino 3.4 index. Over the entire globe, the prediction skill shows strong interannual variation and the mean prediction skills over 28 years are 0.31 and 0.24 for SYS4 and CFSv2, respectively
(Fig. 10a). Most of the years have greater skill than the persistence prediction. The prediction skill of the global zonal wind in both reforecasts shows its highest skill in 1997 and 1998 summer when the ENSO amplitude is strong.

For the Asian monsoon region (Fig. 10b), the mean prediction skill is 0.52 and 0.31 for SYS4 and CFSv2, respectively. The skill is higher in both model predictions than the persistence prediction and the highest skill is apparent in the strong ENSO years in both modeling systems. Figure 11 shows the mean prediction skill of Asian monsoon zonal wind from Fig. 10b, plotted in descending order of the ENSO amplitude and arranged according to the absolute value of the ENSO amplitude. A 5-year moving average is applied both to the ENSO amplitude and the prediction skill ranges from the largest to the smallest ENSO amplitude, in the same manner of Kim et al. (2012). It is clear in both modeling systems that the Asian monsoon prediction skill increases with the ENSO amplitude. This suggests that a significant portion of the Asian monsoon prediction skill in both modeling systems comes from the ENSO forcing (Liang et al. 2009; Yang et al. 2008).

\section{Discussion: Failure in Asian monsoon prediction}

The Asian monsoon appears to be well predicted during years with strong ENSO forcing. In addition, ENSO itself is well predicted in both modeling systems after April/May. However, the monsoon prediction skill, especially the Indian monsoon, is not as high as the ENSO prediction skill. Therefore, it is natural to ask why both modeling systems perform so poorly in predicting the Asian monsoon on seasonal timescales. To answer this question, first we examine the relationship between ENSO and the Asian monsoon from observational and modeling perspectives. Figure 12 shows the simultaneous correlation coefficients between the WYI and SST anomaly for both observations and model predictions for JJA. Observations show that a strong Asian monsoon is associated with SST cooling over the central to eastern Pacific and Indian Ocean, with SST warming over the tropical and northern part of the western Pacific (Fig. 12a). The relationship between ENSO and the monsoon is similar to the observed pattern for both model predictions, with a large temperature gradient between the east-west tropical Oceans (Fig. 12b-c). In both modeling systems, the connection between ENSO and monsoon is much stronger than in the observations, resulting in overly strong impact of ENSO on the Asian monsoon ( $\mathrm{Hu}$ and Huang 2007; Misra and Zhang 2007; Yang et al. 2008). We note that it has been found that the ENSO-monsoon relationship has weakened during recent years since 1980 (Kumar et al. 1999; Rajeevan et al. 2012). However, the 


\section{SST and U850 anomaly in 1982}

(a) OBS: MAY

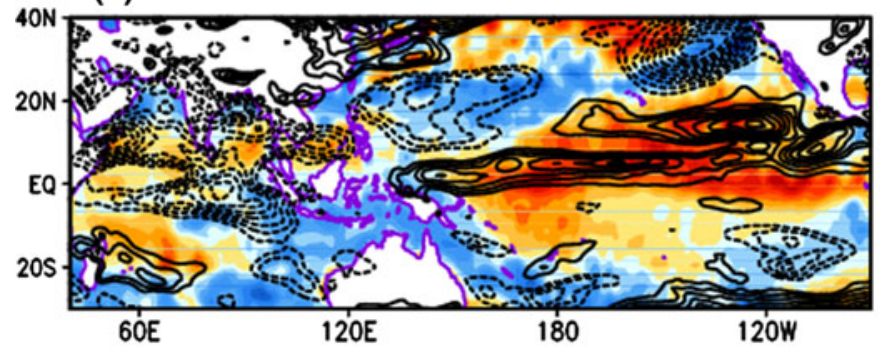

(b) SYS4: MAY

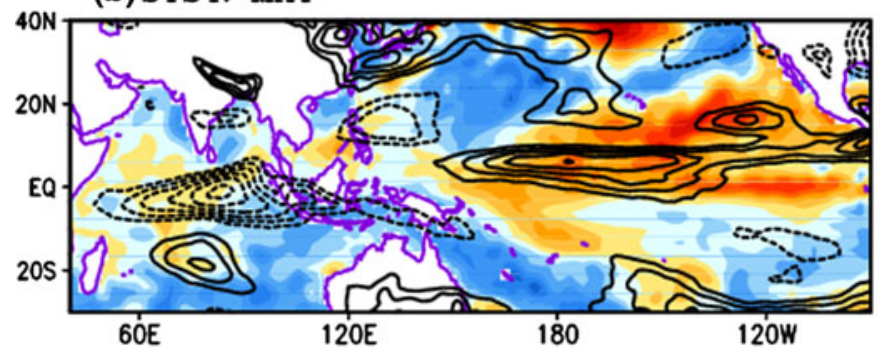

(c) CFSv2: MAY

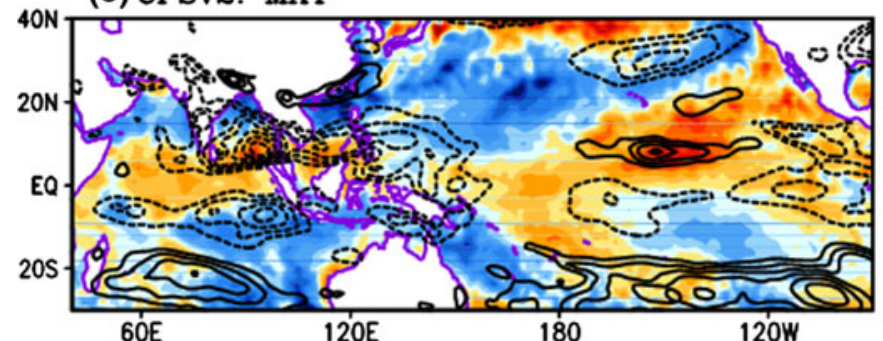

(d) OBS: JUNE

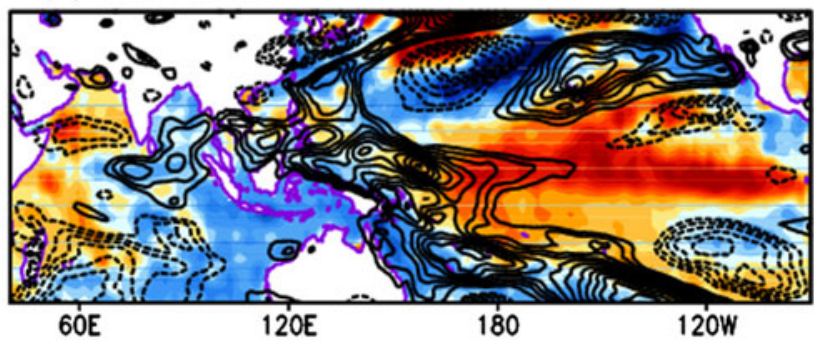

(e) SYS4: JUNE

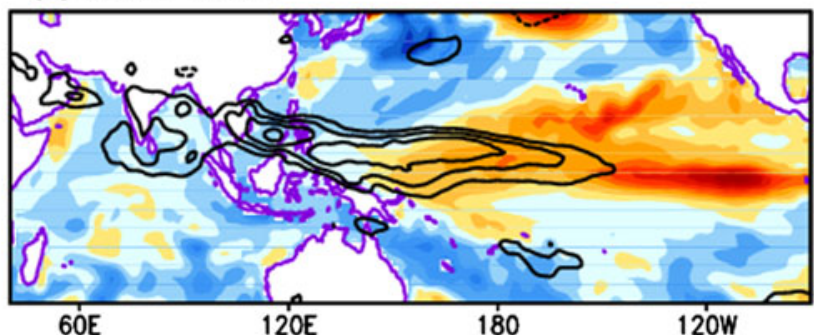

(f) CFSv2: JUNE

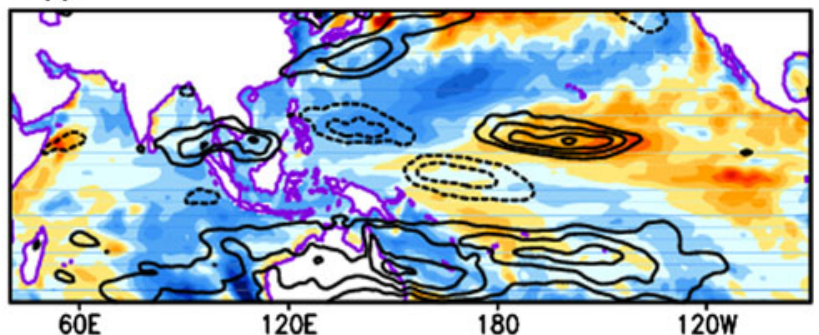

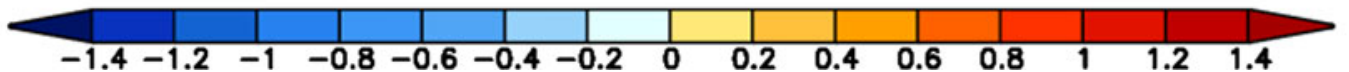

Fig. 13 Zonal wind anomaly at $850 \mathrm{hPa}$ (m/s, contour) and SST anomaly (K, shading) in 1982 for (left) May and (right) June in observation, SYS4 and CFSv2. The contour interval for the zonal wind is $0.5 \mathrm{~m} / \mathrm{s}$

model predictions are unable to capture the recent weakening of the ENSO-monsoon relationship, which results in poorer skill in monsoon prediction. The lack of the capture of the recent ENSO-monsoon weakening could be due to many reasons, including natural internal variability, phase change in multi-decadal variability or model mean biases.

Although the two modeling systems have less skill in predicting the Asian monsoon than ENSO alone, the model predictions show clearly greater prediction skill than persistence prediction. The low skill, especially in CFSv2, results from contributions for a number of years: 1982, 1996, and 2008 (Fig. 10b). The 2003 monsoon seems to be difficult to predict in both modeling systems (Fig. 10b). The persistence prediction in 1996 and 2003 shows negative correlations, indicating that the zonal wind pattern in the initial month (May) changed during the following summer. One interesting fact is that the CFSv2 prediction skill has a strong correlation with the skill in persistence prediction skill (correlations above 0.5).

Here we examine more closely four case studies in which the CFSv2 or SYS4 predictions differ significantly from observation: 1982, 1996, 2003 and 2008 (Figs. 1316). Both SYS4 and CFSv2 failed to predict the monsoon circulation field during 2003. Figure 15 shows the SST and zonal wind anomaly at $850 \mathrm{hPa}$ for May and June from observations and two model predictions. Both models simulate the gross SST pattern and the associated wind pattern well in the zero-month lead (May), with a strong negative SST anomaly in the eastern Pacific and warm anomaly over the central Pacific. The westerly wind anomaly over the western Pacific is well predicted in both models. However, the observed circulation pattern shows dramatic changes in the following month (June) that is not represented by either modeling system, resulting in poor 
SST and U850 anomaly in 1996

(a) OBS: MAY

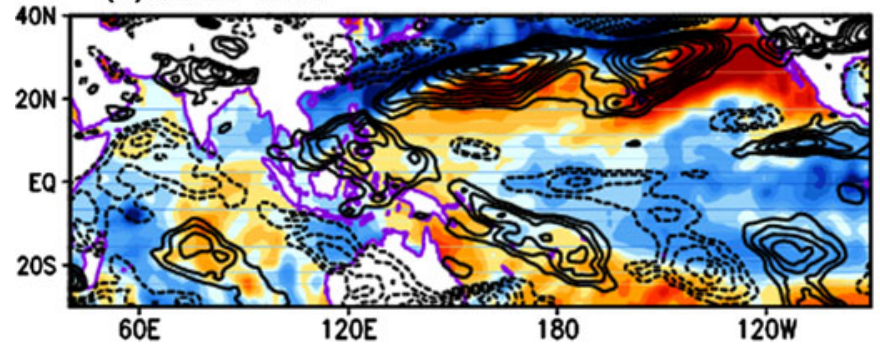

(b) SYS4: MAY

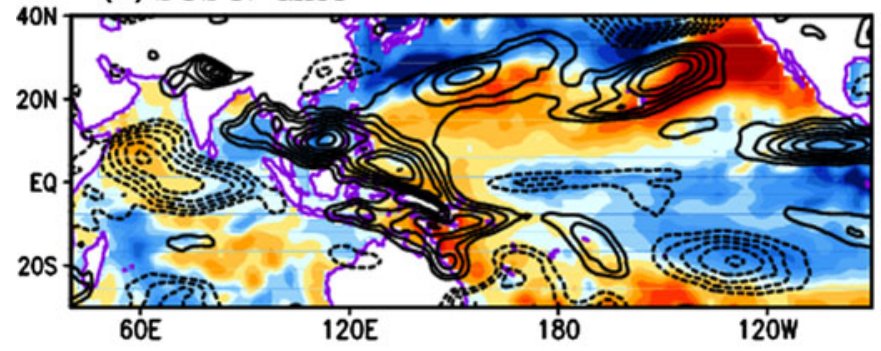

(c) CFSv2: MAY

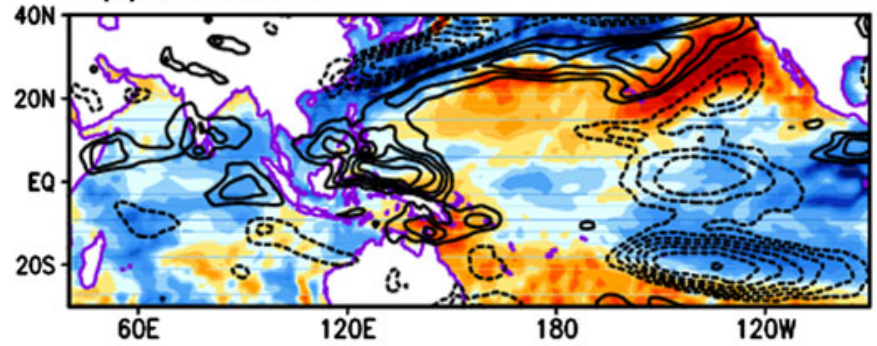

(d) OBS: JUNE

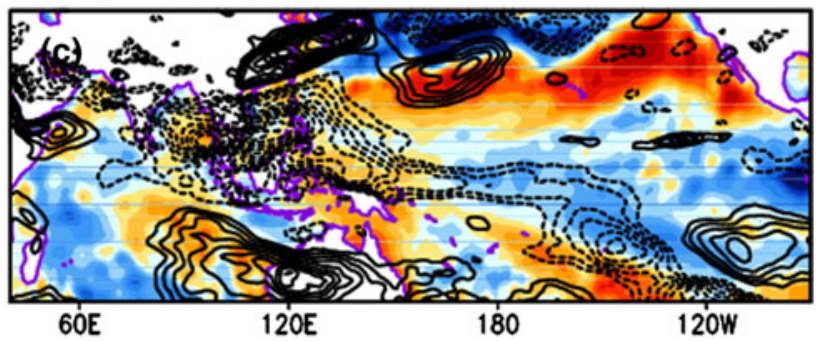

(e) SYS4: JUNE

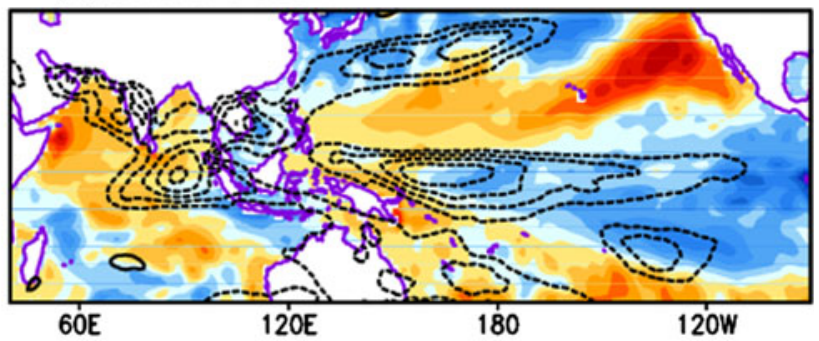

(f) CFSv2: JUNE

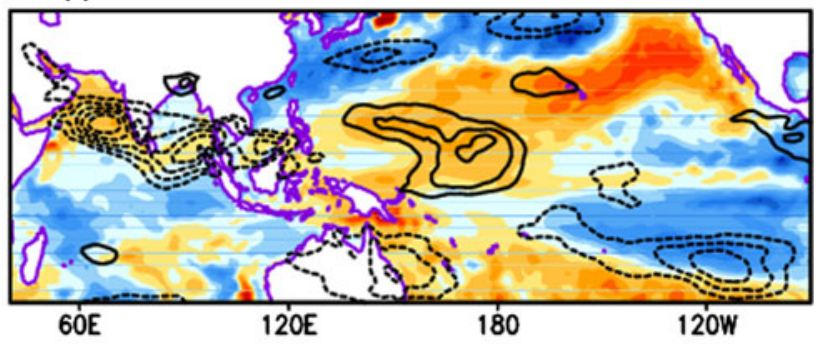

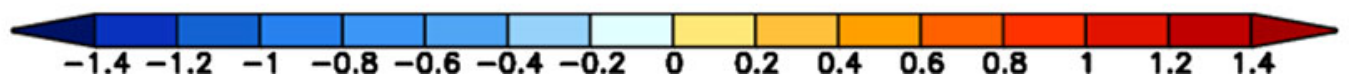

Fig. 14 Same as Fig. 13 except for 1996

prediction skill of monsoon circulations. The underlying SST anomaly is a strong La Nina in both models, while the observation suggests a weaker ENSO anomaly relative to the previous month. The SST pattern over the Indian Ocean is also quite different in the models relative to the observation. Another reason for poor prediction of year 2003 is associated with the existence of a strong MJO event propagating over Africa and into the Indian Ocean during June 2003, which is poorly simulated by both models. Although the prediction of the MJO is beyond the scope in this study, it will be examined in the further work.

Notable failures in monsoon prediction in CFSv2, compared to SYS4, occur in the summers of 1996 and 2008. In May 1996 (Fig. 13b), observations show cooling over the central-east Pacific and western Indian Ocean. The circulation pattern over the Asian monsoon region shows similar features in SYS4 to the observed fields, while both the SST anomaly and the circulation pattern is different from the observations in CFSv2. The observations for June show a broad area of easterly wind anomalies over the Asian monsoon region. The one-month lead prediction in SYS4 represents the June SST anomaly and the wind pattern similar to observations. However, the CFSv2 shows a warm SST anomaly in the central Pacific associated with the different circulation pattern over the western Pacific from the observations. In 2008, the CFSv2 also has an opposite sign for the SST anomaly at June with positive anomaly over the central Pacific, while SYS4 represents the observed strong negative anomaly very well. The skill in 1982 is also different in two modeling systems, even though it is a strong ENSO year (Fig. 13). The SST pattern in CFSv2 for the one-month lead (June) shows a different pattern from the observed SST, thus resulting in a poor prediction of the circulation pattern (Fig. 13).

Here we compared 4 years that show distinct failure in monsoon prediction. However, it is clear that it is not easy 


\section{SST and U850 anomaly in 2003}

(a) OBS: MAY

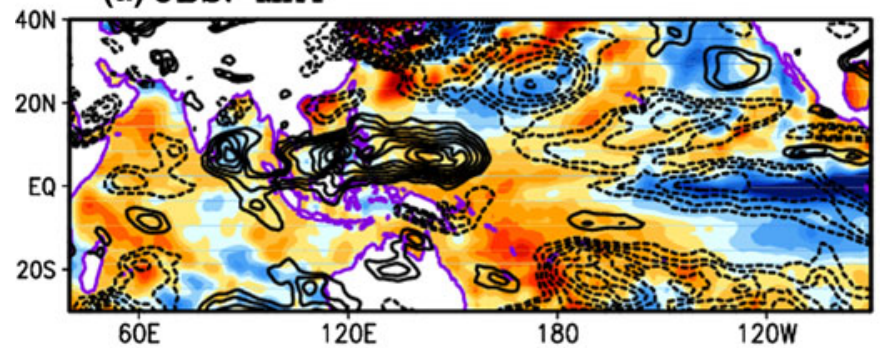

(b) SYS4: MAY

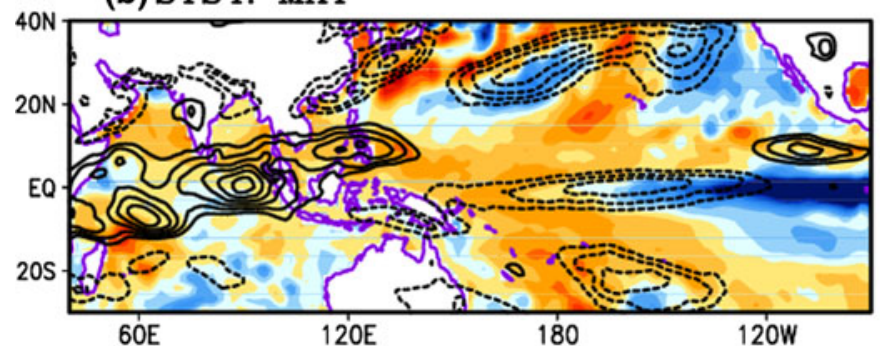

(c) CFSv2: MAY

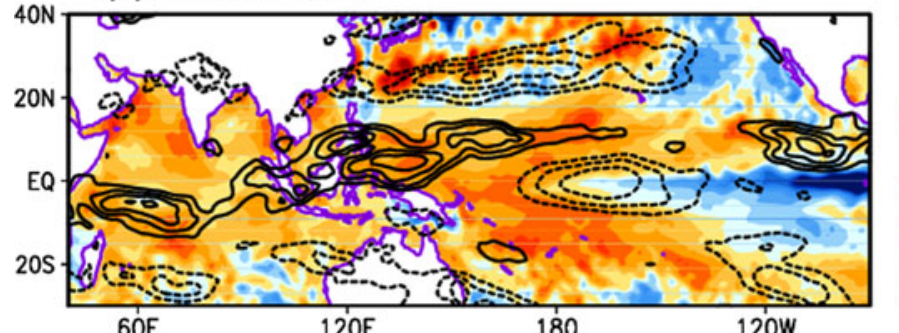

$60 E$ (d) OBS: JUNE

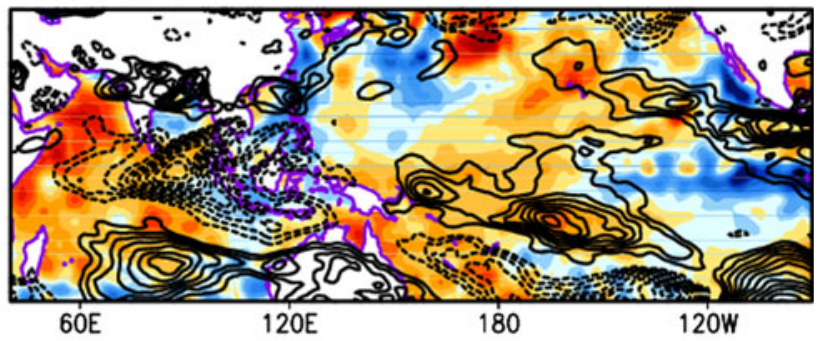

(e) SYS4: JUNE

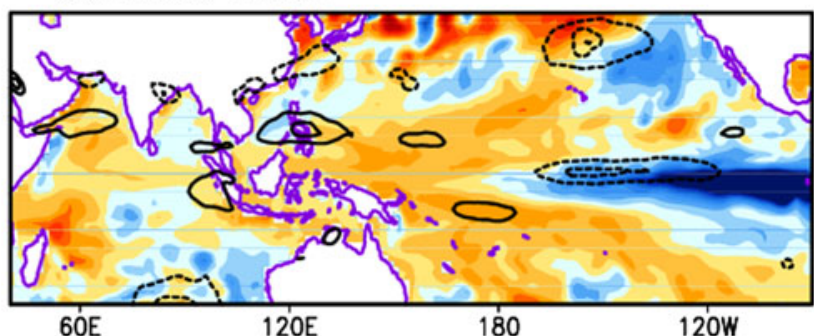

(f) CFSv2: JUNE

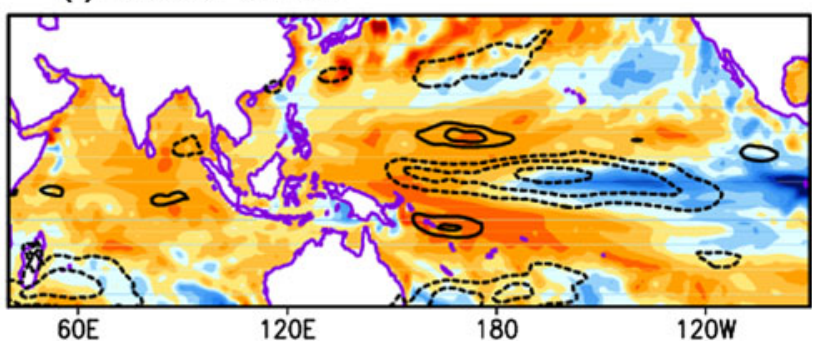

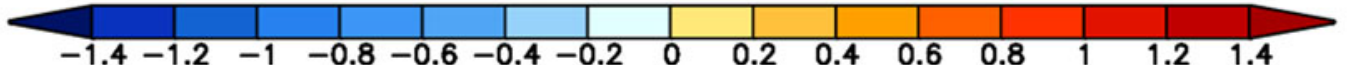

Fig. 15 Same as Fig. 13 except for 2003

to generalize the underlying processes that determine monsoon prediction failure. More analysis is required to understand this problem.

\section{Summary}

This study has examined the seasonal predictive skill of the NH summer using retrospective predictions by the ECMWF System 4 and NCEP CFS version 2. Seasonal predictions of one to three-month lead (initialized in May) for the boreal summer (JJA) have been investigated with 15-16 ensembles for the period 1982-2009. The ensemble means for both reforecasts reproduce realistically the gross pattern of the observed climatology for SST, precipitation and low-level wind, although systematic biases are found. In both SYS4 and CFSv2, a cold bias of SST is found over the equatorial Pacific, North Atlantic, Indian Ocean and a broad region over the Southern Hemisphere and a warm bias is found over the northern part of North Pacific and North Atlantic. Both systems show a dry bias over the East Asia monsoon region and northern part of South America while excessive precipitation is found along the ITCZ, equatorial Atlantic, equatorial Indian Ocean and maritime continent.

The southwest monsoon flow and the Somali Jet are stronger in SYS4, while the south-easterly trade winds over the tropical Indian Ocean, the Somali Jet and the subtropical northwestern Pacific high are weaker in CFSv2 relative to reanalysis products. Both modeling systems simulate the solstice global monsoon mode well, with good representation of the Asian-Australian and Africa monsoons. In both systems, the SST prediction has its greatest skill in the tropical belt, especially over the central and eastern Pacific and equatorial Atlantic where the influence of ENSO is dominant. In the Asian monsoon region, especially over the Indian Ocean, the prediction of precipitation has low skill, where the correlation coefficients 


\section{SST and U850 anomaly in 2008}

(a) OBS: MAY

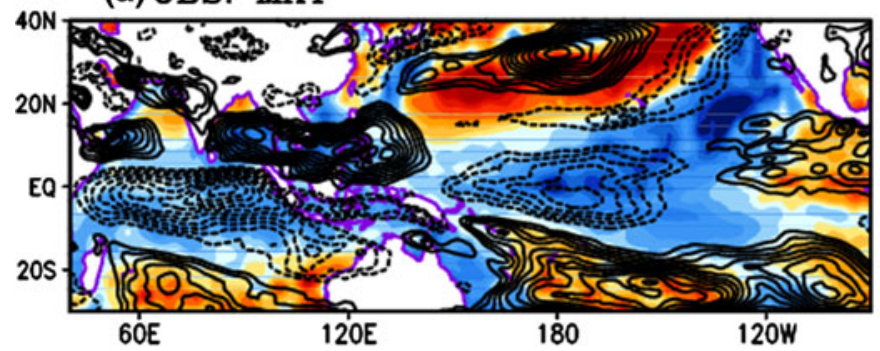

(b) SYS4: MAY

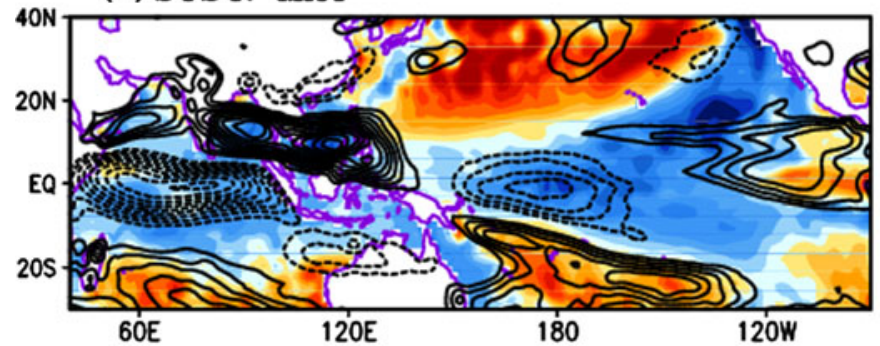

(c) CFSv2: MAY

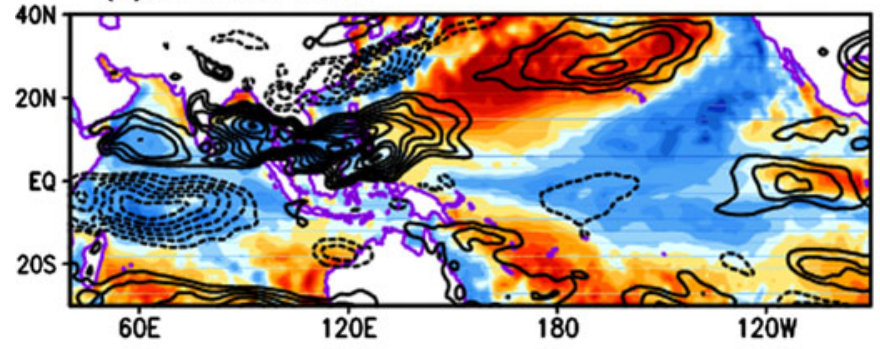

(d) OBS: JUNE

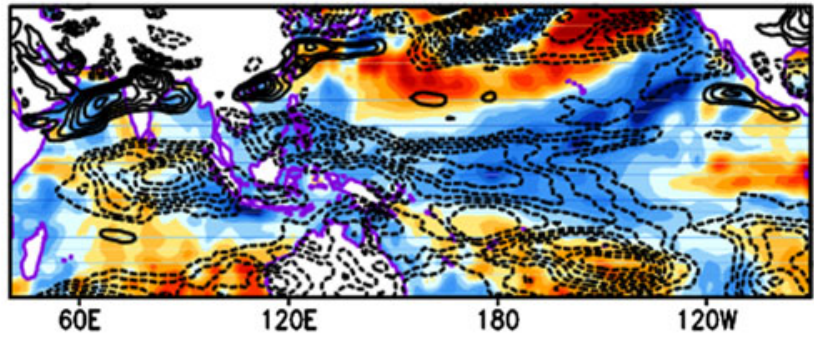

(e) SYS4: JUNE

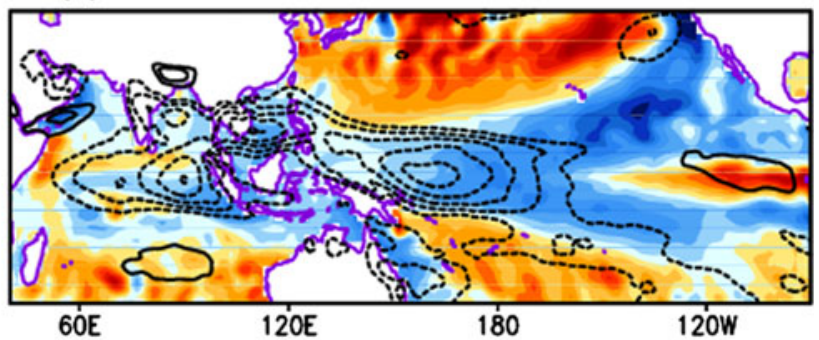

(f) CFSv2: JUNE

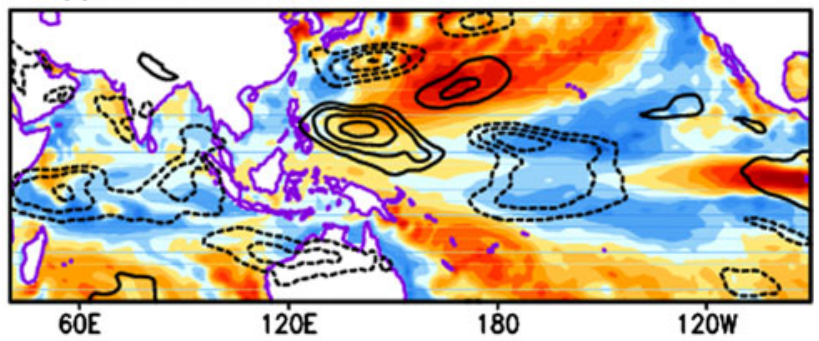

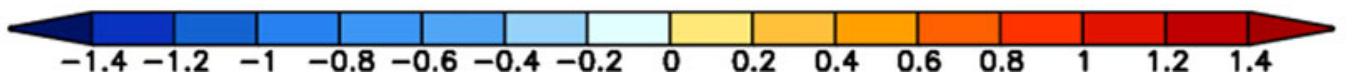

Fig. 16 Same as Fig. 13 except for 2008

do not exceed the significant confidence level. The SYS4 shows greater skill for the low-level wind prediction over the tropical Pacific and Indian Ocean compared to CFSv2 translating into higher predictive skill for the monsoon indices in SYS4 compared to CFSv2. Both reforecasts capture the large-scale South Asian summer monsoon variability quite well, although both models perform poorly in simulating the Indian monsoon circulation.

The two leading principal EOF components in precipitation that are closely related to the ENSO variability are captured well by both models, although the model's eigenvectors show biases in the spatial pattern. Both models capture the main ENSO teleconnection pattern of shifting of the Walker circulation, which induces ascending motion with a wet anomaly across the equatorial central to eastern Pacific and sinking motion with a dry anomaly over the maritime continent and equatorial eastern Indian Ocean in an El Nino summer. The Asian monsoon prediction skill increases with the ENSO amplitude, implying that a significant portion of the Asian monsoon prediction skill comes from the ENSO forcing. However, although both systems perform very well in simulating ENSO and its associated teleconnection patterns, the relationship between ENSO and the monsoon is much stronger than observed, resulting in an overly strong impact of ENSO on the Asian monsoon. The inability of the two models to capture the observed recent weakening of the ENSOmonsoon relationship could be the cause for poor skill in monsoon prediction. Although the two modeling systems have less skill in monsoon prediction than for ENSO prediction, both models clearly show greater skill than persistence prediction.

We have assessed Asian monsoon predictive skill in two reforecast systems. The seasonal monsoon rainfall not only depends on the magnitudes of the slowly varying boundary conditions but also on the seasonal average of the 
intraseasonal component (Charney and Shukla 1981; Webster et al. 1998). Even though ENSO provides a linkage to the strength of the South Asian monsoon, the correlations are still rather weak. This may be due to the role of intraseasonal variability. Hoyos and Webster (2007) found that the greatest difference between years is found in the intraseasonal (30-60 day) band. That is, the degree of variance of a monsoon year comes from the number of intraseasonal events. Earlier, Lawrence and Webster (2002) found that the correlation of the phase of ENSO and the degree of intraseasonal variability was very weak. Thus, intraseasonal variability, possibly a phenomenon independent of ENSO, may dilute the overall impact of ENSO on the predictability of the monsoon. Intraseasonal variability strongly influences regional rainfall and is a source of extended range predictability of monsoon weather (Lawrence and Webster 2001; Webster and Hoyos 2004; Wang et al. 2005a, Hoyos and Webster 2007). Therefore, it is important to assess the prediction skill of the monsoon intraseasonal variability in state-of-the-art ocean-atmosphere coupled forecasting system. Comparison in prediction skill of intraseasonal variability between ECMWF SYS4 and NCEP CFSv2 prediction will be explored in a following study.

Acknowledgments We would like to thank the reviewers for thoughtful and helpful comments. The ECMWF System 4 reforecasts were obtained by the authors through a commercial agreement with ECMWF. The Climate Dynamics Division of the National Science Foundation under grant NSF-AGS 0965610 provided funding support for this research.

Open Access This article is distributed under the terms of the Creative Commons Attribution License which permits any use, distribution, and reproduction in any medium, provided the original author(s) and the source are credited.

\section{References}

Adler RF et al (2003) The version 2 global precipitation climatology project (GPCP) monthly precipitation analysis (1979-present). J Hydrometeorol 4:1147-1167

Anderson D, Stockdale T, Balmeseda M, Ferranti L, Vitart F, Molteni F, Doblas-Reyes F, Mogensen K, Vidard A (2007) Development of the ECMWF seasonal forecast System 3. ECMWF Technical memorandum 503

Berrisford P, Dee D, Fielding K, Fuentes M, Kallberg P, Kobayashi S, Uppala $S$ (2009) The ERA-Interim archive, ERA report series, vol 1. ECMWF, Reading

Charney JG, Shukla J (1981) Predictability of monsoons. In: Lighthill J, Pearce RP (eds) Monsoon dynamics. Cambridge University Press, Cambridge, pp 99-109

Hoyos CD, Webster PJ (2007) The role of intraseasonal variability in the nature of Asian monsoon precipitation. J Clim 20(17):4402-4424

Hu ZZ, Huang B (2007) The predictive skill and the most predictable pattern in the tropical Atlantic: the effect of ENSO. Mon Weather Rev 135:1786-1806
Jin EK et al (2008) Current status of ENSO prediction skill in coupled ocean-atmosphere models. Clim Dyn 31:647-664

Kang IS et al (2002) Intercomparison of the climatological variations of Asian summer monsoon precipitation simulated by 10 GCMs. Clim Dyn 19:383-395

Kim HM, Kang IS, Wang B, Lee JY (2008) Interannual variations of the boreal summer intraseasonal variability predicted by ten atmosphere-ocean coupled models. Clim Dyn 30:485-496

Kim HM, Webster PJ, Curry JA (2012) Seasonal prediction skill of ECMWF System 4 and NCEP CFSv2 retrospective forecast for the Northern Hemisphere Winter. Clim Dyn. doi:10.1007/ s00382-012-1364-6

Kug JS, Kang IS, Choi DH (2008) Seasonal climate predictability with tier-one and tier-two prediction systems. Clim Dyn 31:403-416

Kumar A, Hoerling MP (2000) Analysis of a conceptual model of seasonal climate variability and implications for seasonal predictions. Bull Am Meteorol Soc 81:255-264

Kumar KK, Rajagopalan B, Cane MA (1999) On the weakening relationship between the Indian monsoon and ENSO. Science 284:2156-2159

Kumar KK, Hoerling M, Rajagopalan B (2005) Advancing Indian monsoon rainfall predictions. Geophys Res Lett 32:L08704. doi: 10.1029/2004GL021979

Lawrence D, Webster PJ (2001) Interannual variations of the intraseasonal oscillation in the south Asian summer monsoon region. J Clim 14(3):2910-2922

Lawrence D, Webster PJ (2002) The boreal summer intraseasonal oscillation and the South Asian monsoon. J Atmos Sci 59:1593-1606

Lee JY, Wang B, Kang IS, Shukla J et al (2010) How are seasonal prediction skills related to models' performance on mean state and annual cycle? Clim Dyn 35:267-283

Liang J, Yang S, Hu ZZ, Huang B, Kumar A, Zhang Z (2009) Predictable patterns of Asian and Indo-Pacific summer precipitation in the NCEP CFS. Clim Dyn 32:989-1001

Misra V, Zhang Y (2007) The fidelity of NCEP CFS seasonal hindcasts over Nordeste. Mon Weather Rev 135:618-627

Molteni F, Stockdale T, Balmaseda M, Balsamo G, Buizza R, Ferranti L, Magnusson L, Mogensen K, Palmer T, Vitart F (2011) The new ECMWF seasonal forecast system (System 4). ECMWF Technical Memorandum 656

Pattanaik DR, Kumar A (2010) Prediction of summer monsoon rainfall over India using the NCEP climate forecast system. Clim Dyn 34:557-572

Peng P, Kumar A, Barnston AG, Goddard L (2000) Simulation skills of the SST-forced global climate variability of the NCEP-MRF9 and the Scripps-MPI ECHAM3 models. J Clim 13:3657-3679

Peng P, Kumar A, Wang W (2011) An analysis of seasonal predictability in coupled model forecasts. Clim Dyn 36:419-430

Rajeevan M, Unnikrishnan CK, Preeth B (2012) Evaluation of the ENSEMBLES multi-model seasonal forecasts of Indian summer monsoon variability. Clim Dyn 38:2257-2274

Reynolds RW, Rayner NA, Smith TM, Stokes DC, Wang W (2002) An improved in situ and satellite SST analysis for climate. J Clim 15:1609-1625

Saha S et al (2006) The NCEP climate forecast system. J Clim 19:3483-3517

Saha $\mathrm{S}$ et al (2010) The NCEP climate forecast system reanalysis. Bull Am Meteor Soc 91(8):1015-1057

Stockdale TN, Anderson DLT, Balmaseda MA, Doblas-Reyes FJ, Ferranti L, Mogensen K, Palmer TN, Molteni F, Vitart F (2011) ECMWF seasonal forecast system 3 and its prediction of sea surface temperature. Clim Dyn 37(3-4):455-471. doi: 10.1007/s00382-010-0947-3

Tompkins AM, Feudale L (2010) Seasonal ensemble predictions of West African monsoon precipitation in the ECMWF system 3 
with a focus on the AMMA special observing period in 2006 . Weather Forecast 25:768-788

Wang B, Ding Q (2008) Global monsoon: dominant mode of annual variation in the tropics. Dyn Atmos Oceans 44:165-183

Wang B, Wu R, Lau KM (2001) Interannual variability of Asian summer monsoon: contrast between the Indian and western North Pacific-East Asian monsoons. J Clim 14:4073-4090

Wang B, Ding QH, Fu XH, Kang IS, Jin K, Shukla J, Doblas-Reyes F (2005a) Fundamental challenge in simulation and prediction of summer monsoon rainfall. Geophys Res Lett 32:L15711

Wang W, Saha S, Pan HL, Nadiga S, White G (2005b) Simulation of ENSO in the new NCEP Coupled Forecast System Model. Mon Weather Rev 133:1574-1593

Wang B, Lee JY, Kang IS, Shukla J, Kug JS, Kumar A, Schemm J, Luo JJ, Yamagata T, Park CK (2008) How accurately do coupled climate models predict the leading modes of AsianAustralian monsoon interannual variability? Clim Dyn 30:605-619

Wang B, Liu J, Kim HJ, Webster PJ, Yim SY (2011a) Recent change of the global monsoon precipitation (1979-2008). Clim Dyn. doi:10.1007/s00382-011-1266-Z

Wang W, Xie P, Yoo SH, Xue Y, Kumar A, Wu X (2011b) An assessment of the surface climate in the NCEP climate forecast system reanalysis. Clim Dyn 37:1601-1620
Weaver SJ, Wang W, Chen M, Kumar A (2011) Representation of MJO Variability in the NCEP climate forecast system. J Clim 24(17):4676-4694. doi:10.1175/2011JCLI4188.1

Webster PJ (1995) The annual cycle and the predictability of the tropical coupled ocean-atmosphere system. Meteor Atmos Phys 56:33-55

Webster PJ, Hoyos C (2004) Prediction of monsoon rainfall and river discharge on 15-30 day time scales. Bull Amer Met Soc 85(11):1745-1765

Webster PJ, Yang S (1992) Monsoon and ENSO: selectively interactive systems. Q J R Meteor Soc 118:877-926

Webster PJ, Magana VO, Palmer TN, Shukla J, Tomas RA, Yanai M, Yasunari T (1998) Monsoons: processes, predictability and the prospects for prediction. J Geophys Res 103:14451-14510

Xue Y, Huang B, Hu ZZ, Kumar A, Wen C, Behringer D (2011) An assessment of oceanic variability in the NCEP climate forecast system reanalysis. Clim Dyn 37:2511-2539

Yang S, Zhang Z, Kousky VE, Higgins RW, Yoo SH, Liang J, Fan Y (2008) Simulations and seasonal prediction of the Asian summer monsoon in the NCEP Climate Forecast System. J Clim 21:3755-3775

Yang S, Jiang Y, Zheng D, Higgins RW, Zhang Q, Kousky VE, Wen M (2009) Variations of U.S. regional precipitation and simulations by the NCEP CFS: focus on the Southwest. J Clim 22:3211-3231 